\title{
Modifiable risk factors for the prevention of bladder cancer: a systematic review of meta-analyses
}

\author{
Abdulmohsen H. Al-Zalabani ${ }^{1} \cdot K_{\text {Kelly F. J. Stewart }}^{2}$ (D) Anke Wesselius $^{2}$ • \\ Annemie M. W. J. Schols ${ }^{3}$ Maurice P. Zeegers ${ }^{2}$
}

Received: 8 December 2015/Accepted: 8 March 2016/Published online: 21 March 2016

(C) The Author(s) 2016. This article is published with open access at Springerlink.com

\begin{abstract}
Each year, 430,000 people are diagnosed with bladder cancer. Due to the high recurrence rate of the disease, primary prevention is paramount. Therefore, we reviewed all meta-analyses on modifiable risk factors of primary bladder cancer. PubMed, Embase and Cochrane database were systematically searched for meta-analyses on modifiable risk factors published between 1995 and 2015. When appropriate, meta-analyses (MA) were combined in meta-meta-analysis (MMA). If not, the most comprehensive MA was selected based on the number of primary studies included. Probability of causation was calculated for individual factors and a subset of lifestyle factors combined. Of 1496 articles identified, 5 were combined in MMA and 21 were most comprehensive on a single risk factor. Statistically significant associations were found for current (RR 3.14) or former (RR 1.83) cigarette smoking, pipe (RR 1.9) or cigar (RR 2.3) smoking, antioxidant supplementation (RR
\end{abstract}

Review registration: PROSPERO CRD42015023411.

Abdulmohsen H. Al-Zalabani, and Kelly F. J. Stewart have contributed equally to this work.

Kelly F. J. Stewart

k.stewart@maastrichtuniversity.nl

1 Department of Family and Community Medicine, College of Medicine, Taibah University,

P.O. Box 42317, Madinah 41541, Saudi Arabia

2 Department of Complex Genetics, School of Nutrition, and Translational Research in Metabolism (NUTRIM), Maastricht University Medical Centre, P. O. Box 616, 6200 MS Maastricht, The Netherlands

3 Department of Respiratory Medicine, School of Nutrition and Translational Research in Metabolism (NUTRIM), Maastricht University Medical Centre, P. O. Box 616, 6200 MS Maastricht, The Netherlands
1.52), obesity (RR 1.10), higher physical activity levels (RR 0.86 ), higher body levels of selenium (RR 0.61) and vitamin $\mathrm{D}$ (RR 0.75), and higher intakes of: processed meat (RR 1.22), vitamin A (RR 0.82), vitamin E (RR 0.82), folate ( $R R$ 0.84 ), fruit (RR 0.77), vegetables (RR 0.83), citrus fruit (RR 0.85 ), and cruciferous vegetables (RR 0.84). Finally, three occupations with the highest risk were tobacco workers (RR 1.72), dye workers (RR 1.58), and chimney sweeps (RR 1.53). The probability of causation for individual factors ranged from 4 to $68 \%$. The combined probability of causation was $81.8 \%$. Modification of lifestyle and occupational exposures can considerably reduce the bladder cancer burden. While smoking remains one of the key risk factors, also several diet-related and occupational factors are very relevant.

Keywords Bladder cancer - Prevention - Risk factors . Lifestyle $\cdot$ Obesity $\cdot$ Occupation $\cdot$ Smoking

\section{Introduction}

The International Agency for Research on Cancer (IARC) estimated that worldwide 430,000 people were diagnosed with bladder cancer in 2012, with an age-standardised rate (ASR) of 5.3 per 100,000 people. Incidence of bladder cancer is particularly high in males with $77 \%$ of the cases, ranking it the 7th highest on incidence and 9th highest on mortality. For females it is the 19th highest on incidence and 17th highest on mortality. The incidence of bladder cancer is almost 3 times higher in more developed countries compared to less developed countries (ASR of 9.5 and 3.3 per 100,000 respectively) [1].

Several genetic polymorphisms have been proposed to be associated with the development of bladder cancer. 
However, genetic effects can explain 'only' $7 \%$ of the bladder cancer incidence in western populations [2], and therefore, risk factors related to lifestyle, environmental, and occupational exposures could potentially play an important role in the development of this disease. Over the years, multiple external risk factors have been proposed. Well-established risk factors are tobacco consumption, occupational exposure, such as to aromatic amines and Polycyclic Aromatic Hydrocarbons (PAHs), and infection with Schistosoma hematobium [3]. Whereas smoking is the most important risk factor in developed countries, $S$. hematobium infection accounts for the largest burden in African countries [4, 5]. Additional suggested risk factors are, amongst others, alcohol consumption, coffee intake, low fruit, and vegetable consumption, low selenium and vitamin $\mathrm{E}$ intake, pollution of drinking water, and several medical treatments $[3,6]$.

Exposure to some of the key risk factors of bladder cancer has been successfully reduced in the population. For example, the reduction in exposure to aromatic amines seemed to be directly related to a reduction in bladder cancer incidence [7]. Men are generally more exposed to occupational risk factors of bladder cancer and it is estimated that $7.1 \%$ of the bladder cancer cases in men can be attributed to occupational factors [8]. Also, the prevalence rates of smoking have been declining significantly over the past decades, although the absolute number of smokers has been increasing due to the growing world population [9]. Because men smoke more than women, the percentage of cases attributable to smoking is higher in males than in females: $42.8 \%$ (males) versus $25.7 \%$ (females) in Europe, and $34.3 \%$ (males) versus $30.1 \%$ (females) in the United States [10]. This higher prevalence of smoking among men also explains part of the discrepancy in incidence between men and women [11]. Despite the reduction in exposure to some risk factors, significant exposure, and thus disease, remains. This means that the burden on the health care system will remain substantial especially when considering that at least $50 \%$ of bladder cancers recur [12] and long-term monitoring of patients is required, resulting in the highest per patient lifetime costs amongst all cancers [13]. For example, in the US, the annual cost of care of bladder cancer was estimated to be \$US4 billion. Therefore, primary prevention is paramount, particularly because many of the risk factors are modifiable and therefore preventable.

Prioritising control measures should be evidence-based. To this end, an accessible and comprehensive overview is needed of the modifiable risk factors in the development of bladder cancer, including estimates of public health impact. To our knowledge, no quantitative overview has been published addressing all modifiable risk factors of bladder cancer. Therefore, our aim was to give an overview of the current state of knowledge, at the highest level of evidence, with regard to modifiable lifestyle, environmental, and occupational risk factors for development of bladder cancer by performing a systematic review of meta-analyses (MAs), in combination with a series of meta-meta-analyses (MMAs).

\section{Methods}

This systematic review was registered with PROSPERO (identification number CRD42015023411) [14]. Where relevant, the publication is written in accordance to the PRISMA guidelines [15].

\section{Search strategy}

A systematic literature search was performed up to September 2015 in PubMed, Embase, and the Cochrane database to identify published articles of MAs and pooled analyses describing the association between lifestyle, environmental, and occupational risk factors and the development of bladder cancer. In addition, PROSPERO was searched and authors of registered but not published reviews were contacted. Finally forward and backward referencing of relevant publications was checked for additional publications.

The database was searched using the following search terms: "urinary bladder neoplasms"[MeSH Terms], "urinary bladder neoplasms"[All Fields], "bladder cancer", combined with systematic[sb], meta-analysis[Title/Abstract], meta-analysis[Publication Type], systematic review[Text Word], pooled analysis[Text Word].

\section{Selection criteria for publications}

A first screening was done based on the title and abstract. Articles were considered for inclusion if they were MAs or pooled analyses describing the association between modifiable risk factors and development of bladder cancer, written in English. Inclusion was limited to articles published from 1995, as during the 1990s systematic reviews and meta-analyses started to replace narrative reviews, and methods and terminology were well established by that time [16]. When the references could not be rejected with certainty, the full texts were obtained and a second screening was done. One article may report multiple MAs on different exposures.

The exposure of interest was any modifiable risk factor. 'Modifiable' was defined as a risk factor that is in any way reasonably modifiable, meaning that genetic and medical conditions were excluded as these are generally not modifiable. The outcome of interest was defined as incidence of 
bladder cancer as a binary outcome. Studies that included estimates based on prevalence or mortality were used as a proxy for incidence when estimates on incidence only were not available. Studies presenting results on genitourinary cancers without giving estimates for bladder cancer alone and studies reporting on urothelial cancer alone were excluded. Additionally, pooled risk estimates had to be presented with the accompanying $95 \%$ confidence interval, accepted as odds ratio (OR), risk ratio (RR), hazard ratio (HR), standardised incidence ratio (SIR), or effect size (ES) if the latter consisted of a combination of the previously mentioned ratios. For the purpose of this paper, these estimates are all referred to as relative risks (RR).

\section{Data extraction}

Data was extracted by AA and all entries were doublechecked completely for errors by KS. Any disagreement was discussed between the review authors until consensus was reached. When needed, authors of publications were contacted for additional information.

For each article, the following data was extracted when available: first author, year of publication, journal, risk factor(s) studied, number of events, types of studies included, number of studies included, type of risk estimate (OR, RR, SIR), outcome variable (incidence, prevalence, mortality, or combination), and per MA (statistical procedure): the exposures that were compared, the risk estimate and the $95 \%$ confidence interval, a measure of heterogeneity, the number of primary studies included, and a measure of publication bias.

\section{Selection criteria for estimates}

The estimates to be included had to be based on a minimum of two primary studies. They were selected based on the following list of decisions, and in this order: (1) bladder cancer only over urothelial cancers, (2) overall estimates over sub-group estimates, (3) more adjusted estimates over less adjusted estimates, (4) smoking adjusted over other adjustments, (5) incidence over prevalence or mortality, (6) random effects model over fixed effects model, and (7) pooling of cohort studies over pooling of case-control or cross-sectional studies.

\section{Synthesis of results}

If only one article was available on a specific risk factor, these estimates were included directly. If multiple articles were available, we selected the most comprehensive MA. This could occur in one of two ways. (1) The preferred method was to combine two MAs in a MMA to obtain an overall estimate based on the largest number of studies.
However, we considered this only appropriate if the level of overlap between the primary studies included in each publication was no more than $50 \%$, measured as the percentage of studies of the smaller publication that overlapped with those of the larger publication. In addition, the exposure categories had to be comparable enough to be combined. (2) If, by following this rule, it was not possible to combine publications, the most comprehensive publication was included, based on the largest number of included primary studies. Basing this on the largest number of studies, rather than the largest sample size, was done because it was often not possible to determine the publication with the largest sample size due to insufficient data in the publication.

MMA was performed using a random-effects model. Heterogeneity was assessed between the included MAs using the $\mathrm{I}^{2}$ statistic [17]. All statistical analyses were carried out in STATA V13.0 software and $p$ values of 0.05 or below, or a confidence level of $95 \%$, were considered statistically significant.

In order to provide a measure of public health impact, a probability of causation [18] (POC) was calculated for those risk estimates that were found to be significantly associated with the risk of bladder cancer. In addition, a combined POC [18] was calculated for the lifestyle factors that one can be exposed to at one time. Careful attention was paid to avoid overlapping exposures, such as vitamin C intake, and fruit and vegetable consumption. In that case the most all-inclusive factor was included. No such combined estimate was calculated for all occupational factors combined, as one will unlikely be exposed to multiple occupations at one time.

POC can be interpreted as the percentage of exposed cases that are attributable to the exposure (e.g. the number of cases among smokers that are attributable to smoking). In case of a protective factor this should be read as the proportion of non-exposed cases that are attributable to the fact that they are non-exposed (e.g. the number of cases among people with low fruit and vegetable intake that are attributable to the low fruit and vegetable intake).

\section{Role of the funding source}

The funding body was not involved in the study design; in the collection, analysis, or interpretation of data; in the writing of the report; or in the decision to submit the paper for publication.

\section{Results}

Figure 1 shows the literature search and selection process. A total of 1,496 articles were identified, from which 126 articles were selected based on the title and abstract for 


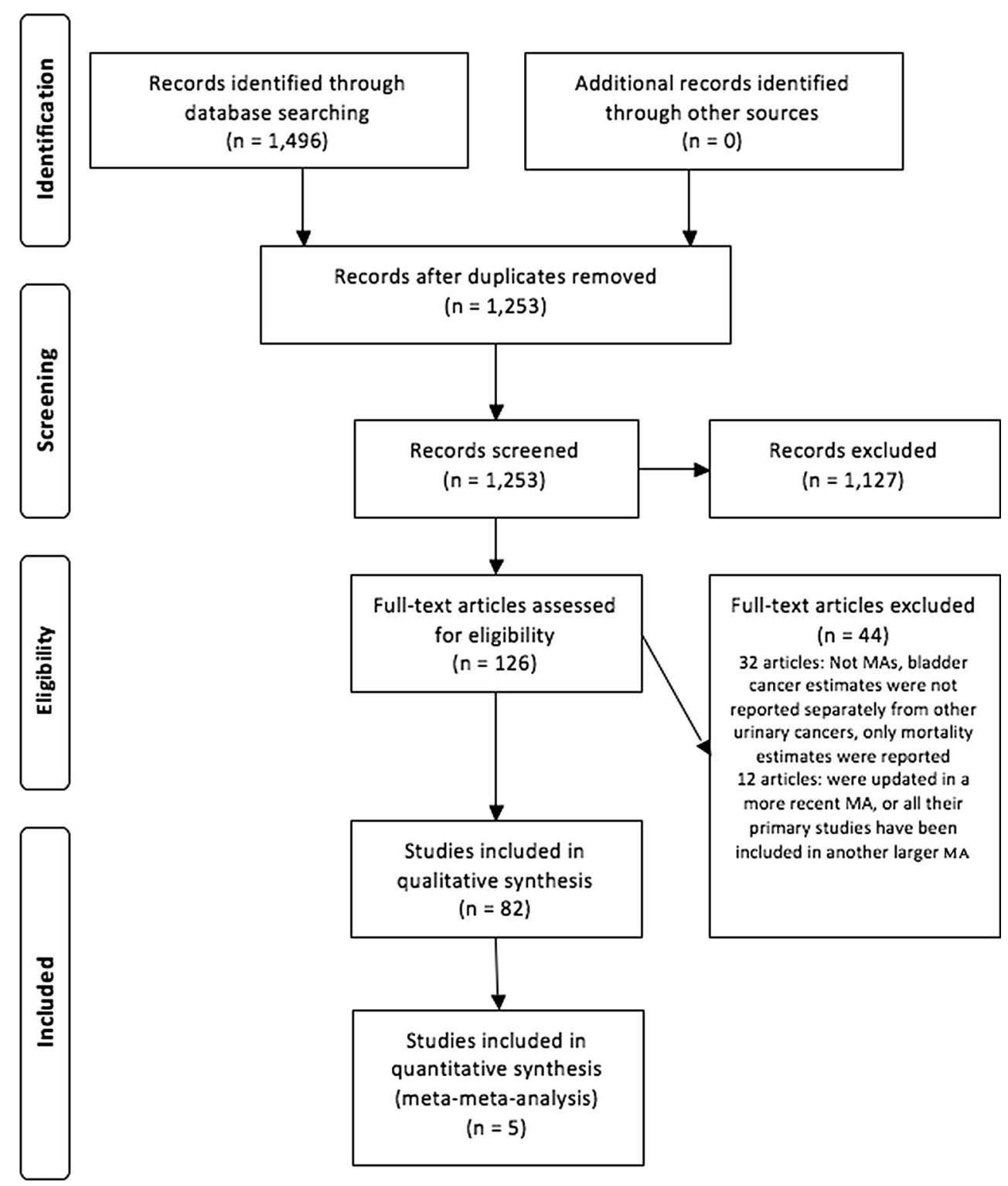

Fig. 1 Flow diagram of literature search and selection process

further evaluation. Of these, 32 articles were excluded (Appendix 1) for the following reasons: not being a MA, bladder cancer estimates were not reported separately from other urinary cancers, no risk estimate reported, or only mortality estimates were reported. Furthermore, 12 articles were excluded because all included primary studies were also part of a larger MA or because an update was available. This resulted in a total of 82 eligible articles (Appendix 2). Of these 82 articles, 21 articles were selected as the most comprehensive MA for a single risk factor, and five articles were combined in two MMAs, together reporting results for 36 risk factors. The statistically significant results from all most comprehensive MAs, totalling 19 lifestyle factors and 48 occupational factors, are summarised in Table 1 and illustrated in Figs. 2 and 3, for the increased and decreased risks respectively.

\section{Lifestyle factors}

Four general topics emerged from the literature search with regard to lifestyle: dietary factors, consumption of tobacco, alcohol consumption, and physical activity.

\section{Dietary factors}

Fruit and vegetable The MA by Yao et al. [19] was selected as the most comprehensive publication for overall fruit and vegetable intake and reported significant 


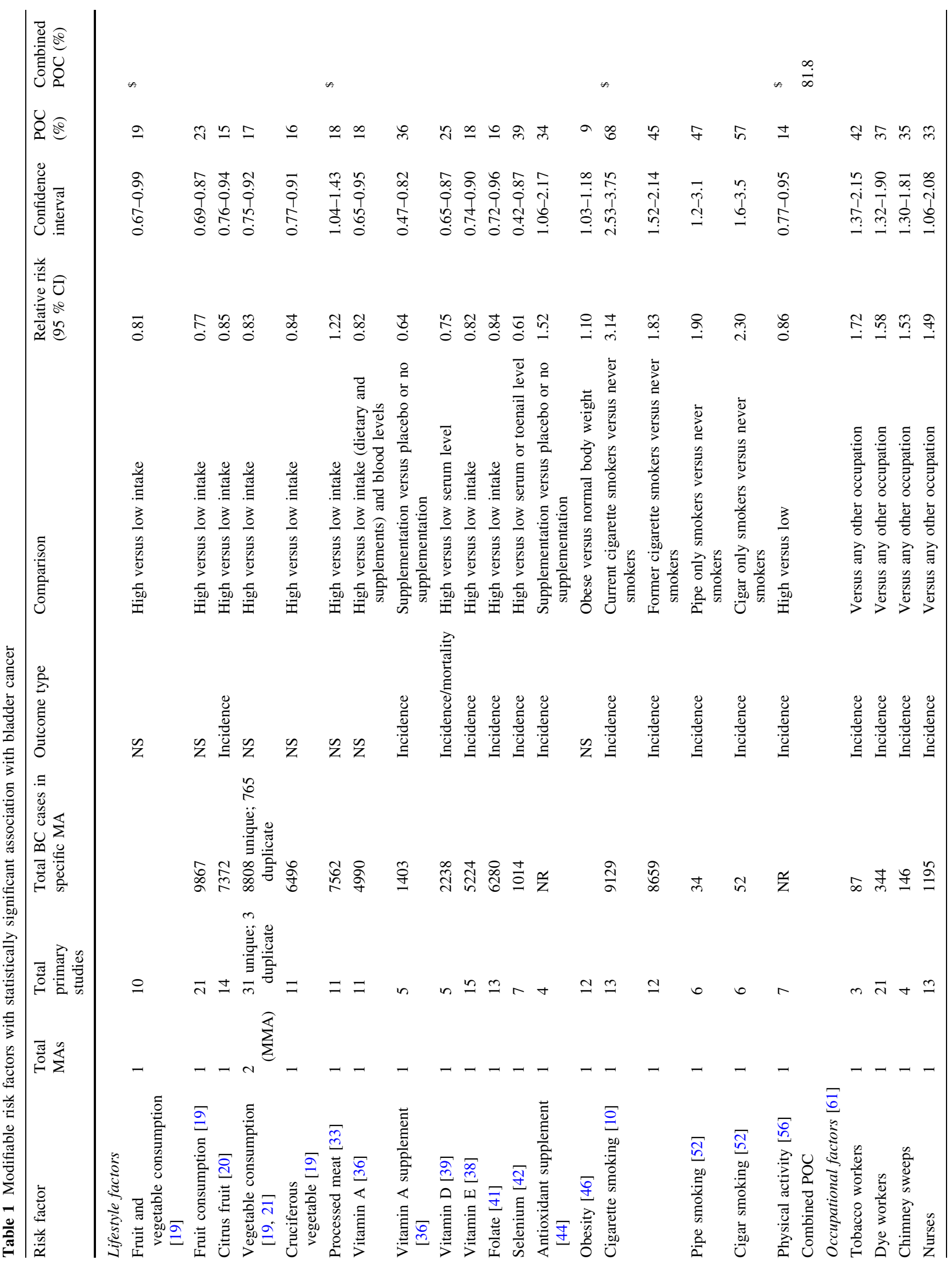




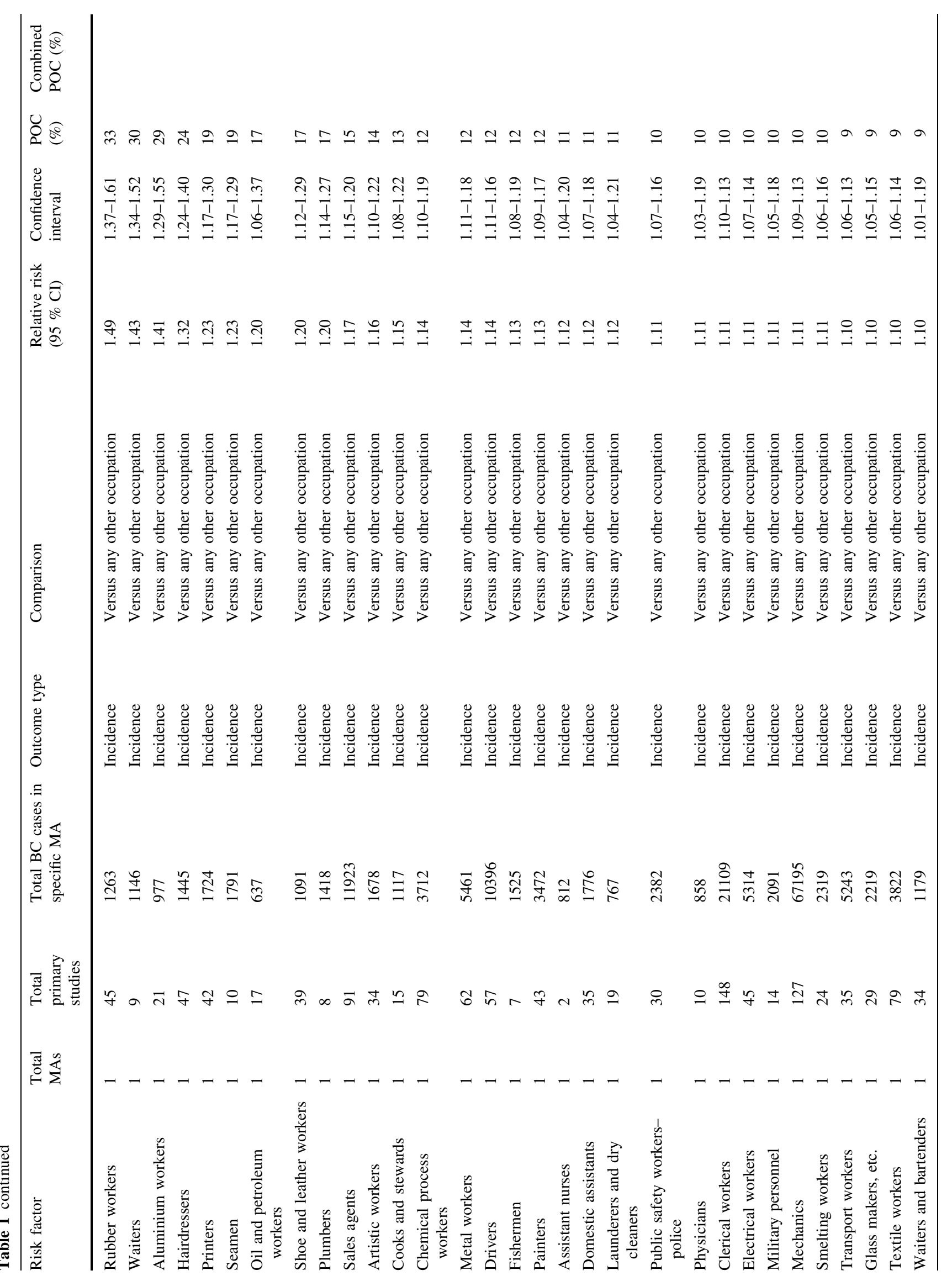




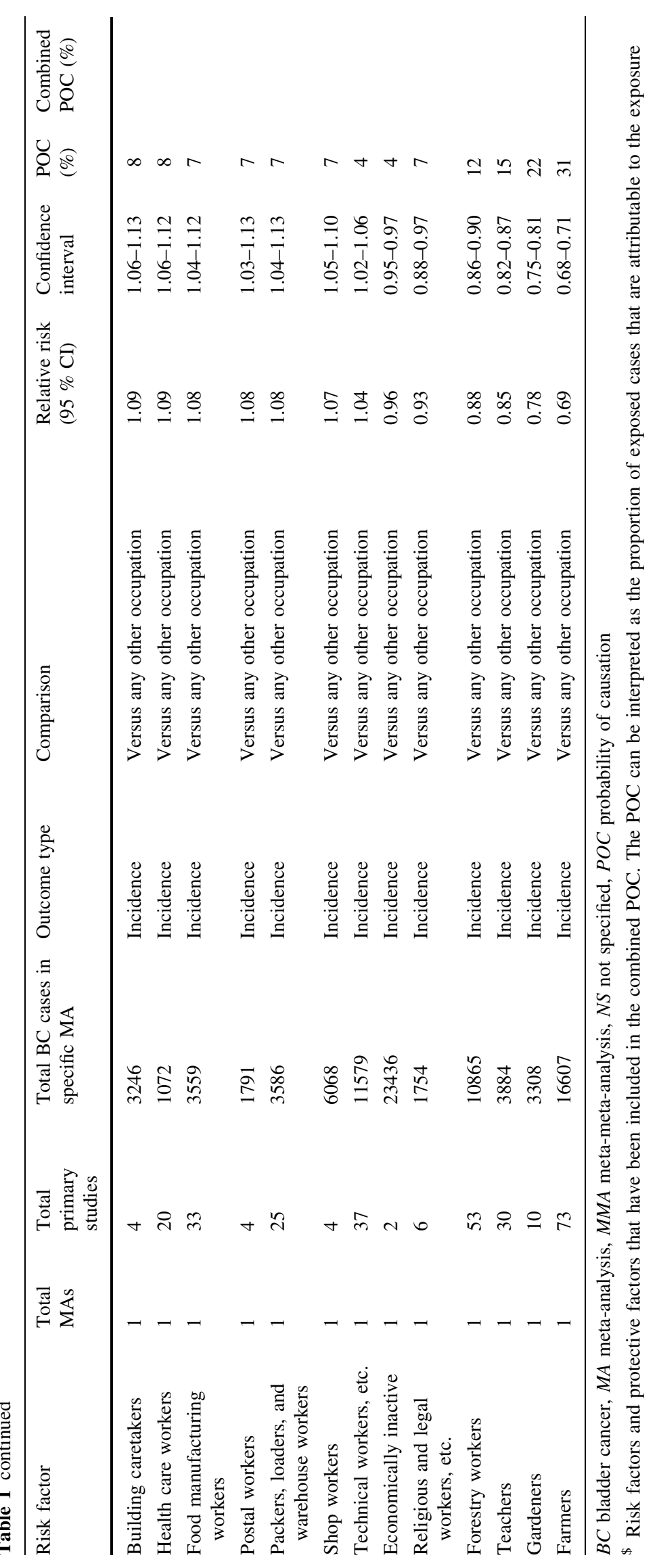




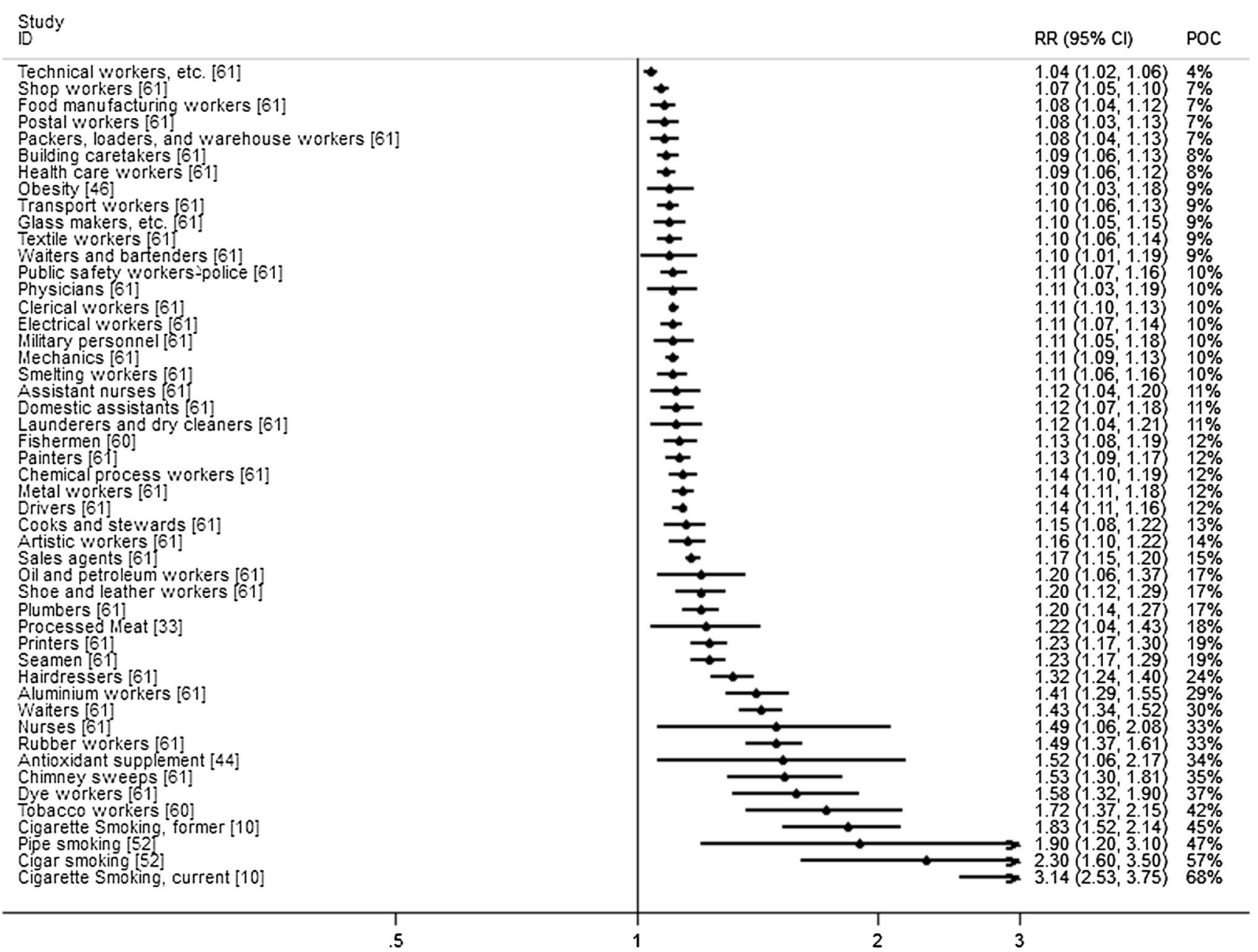

Fig. 2 Forest plot of significantly increased risks

protective effect on bladder cancer (RR $0.81 ; 95 \% \mathrm{CI}$ $0.67-0.99 ; \mathrm{I}^{2}=58.4 \% ; \mathrm{n}=10$ ).

Fruit only MA by Yao et al. [19] was selected as most comprehensive for consumption of overall fruit and the MA by Liang et al. [20] for intake of citrus fruit (e.g. oranges, lemons, limes, and grapefruits;). Overall fruit was associated with a reduced risk of bladder cancer (RR 0.77; $95 \%$ CI $0.69-0.87 ; \mathrm{I}^{2}=54.9 \% ; \mathrm{n}=27$ ) as were citrus fruit (highest vs. lowest intake: RR 0.85; $95 \%$ CI $0.76-0.94 ; \mathrm{I}^{2}=72.1 \% ; \mathrm{n}=14$ ). Yao et al. [19] reported significant publication bias for overall and citrus fruit intake.

Vegetables only By pooling results from Yao et al. [19] and Steinmaus et al. [21] in a MMA, the most comprehensive estimate could be obtained for overall vegetable consumption $(\mathrm{n}=31$ unique and $\mathrm{n}=3$ duplicate primary studies). The MA by Yao et al. [19] was selected as the most comprehensive publication for cruciferous vegetables. Consumption of overall vegetables (RR 0.83; $95 \%$ CI $\left.0.75-0.92 ; \mathrm{I}^{2}=0.0 \% ; \mathrm{n}=21+8\right)$ and cruciferous vegetables specifically (RR 0.84 ; $95 \%$ CI $0.77-0.91$; $\mathrm{n}=11$ ), resulted in a reduced risk of bladder cancer.

\section{Total fluid}

Bai et al. [22] was the most comprehensive estimate and found no statistically significant association between total fluid intake and bladder cancer (RR 1.12; $95 \%$ CI $0.94-1.33 ; \mathrm{I}^{2}=82.8 \%$; $\mathrm{n}=14$ ).

\section{Tea}

The MA by Qin et al. [23] was selected as most comprehensive and they found a significant protective effect for black tea consumption (RR 0.79; $95 \%$ CI 0.59-0.99; $\left.\mathrm{I}^{2}=33.1 \% ; \mathrm{n}=7\right)$ but not for overall and green tea consumption. 
Study

ID

$\mathrm{RR}(95 \% \mathrm{Cl}) \quad \mathrm{POC}$

\begin{tabular}{|c|c|c|}
\hline Selenium [42] & - & $0.61(0.42,0.87) \beta 9 \%$ \\
\hline Vitamin A supplement [36] & & $0.64(0.47,0.82 \beta 6 \%$ \\
\hline Farmers [61] & + & $0.69(0.68,0.71) 1 \%$ \\
\hline Vitamin D [39] & & $0.75(0.65,0.87) 5 \%$ \\
\hline Fruit consumption [19] & $\rightarrow$ & $0.77(0.69,0.87) 3 \%$ \\
\hline Gardeners [61] & $\rightarrow$ & $0.78(0.75,0.81) 2 \%$ \\
\hline Fruit and vegetable consumption [19] & & $0.81(0.67,0.99) 19 \%$ \\
\hline Vitamin A [36] & & $0.82(0.65,0.95) 18 \%$ \\
\hline Vitamin E [38] & $\rightarrow$ & $0.82(0.74,0.90) 18 \%$ \\
\hline Vegetable consumption $[19,21]$ & $\longrightarrow$ & $0.83(0.75,0.92) 17 \%$ \\
\hline Cruciferous vegetable [19] & $\rightarrow$ & $0.84(0.77,0.91) 16 \%$ \\
\hline Folate [41] & $ـ$ & $0.84(0.72,0.96) 16 \%$ \\
\hline Citrus fruit [20] & $\longrightarrow$ & $0.85(0.76,0.94) 15 \%$ \\
\hline Teachers [61] & $\rightarrow$ & $0.85(0.82,0.87) 15 \%$ \\
\hline Physical activity [56] & $\cdots$ & $0.86(0.77,0.95) 14 \%$ \\
\hline Forestry workers [61] & 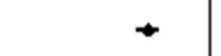 & $0.88(0.86,0.90) 12 \%$ \\
\hline Religious and legal workers, etc. [61] & $\rightarrow$ & $0.93(0.88,0.97) \%$ \\
\hline Economically inactive [61] & $\bullet$ & $0.96(0.95,0.97) \%$ \\
\hline
\end{tabular}

Fig. 3 Forest plot of significantly decreased risks

\section{Coffee}

Six MAs [24-28] reported on the association between coffee consumption and bladder cancer risk, of which Villanueva et al. [27], Yu et al. [26], and $\mathrm{Wu}$ et al. [29] could be combined into a single estimate to provide the most comprehensive estimate $(\mathrm{n}=38$ unique and $\mathrm{n}=3$ duplicate primary studies). No statistically significant association was observed, with substantial heterogeneity (RR $1.12 ; \quad 95 \% \quad$ CI $\quad 0.80-1.44 ; \quad I^{2}=94.2 \%$; $\mathrm{n}=18+9+6)$.

\section{Sweetened carbonated beverages}

Only one MA by Boyle et al. [30] was identified, reporting on the association between sweetened carbonated beverage consumption and risk of bladder cancer. No statistically significant association was found (RR 1.13; $95 \%$ CI $0.89-1.45 ; \mathrm{n}=5$ ).
Milk and dairy products

As reported by Mao et al. [31], which was selected as most comprehensive, overall milk, skim milk, and fermented milk were associated with a significantly reduced incidence of bladder cancer (milk: RR 0.84; $95 \%$ CI $0.72-0.97$; $\mathrm{I}^{2}=70.1 \% ; \mathrm{n}=16$; skim milk: RR $0.47 ; 95 \%$ CI $0.18-0.79 ; \mathrm{I}^{2}=0 ; \mathrm{n}=2$; fermented milk: RR 0.69; $95 \%$ CI $0.47-0.91 ; \mathrm{I}^{2}=62.5 ; \mathrm{n}=5$ ). In contrast, consumption of whole milk was associated with a significantly increased risk of bladder cancer (RR 2.23; $95 \%$ CI 1.45-3.00; $\mathrm{I}^{2}=0 ; \mathrm{n}=2$ ).

\section{Fish}

The MA by Li et al. [32] was the only MA that studied the association between fish consumption and bladder cancer and reported no statistically significant association (RR 0.86; $95 \%$ CI 0.61-1.12). 


\section{Meat}

The MA by $\mathrm{Li}$ et al. [33] was selected as most comprehensive and they found an increased risk of bladder cancer associated with processed meat (RR 1.22; $95 \%$ CI $1.04-1.43 ; \mathrm{n}=11$ ) but not with red meat (RR 1.15; $95 \%$ CI $0.97-1.36 ; \mathrm{n}=14$ ).

\section{Alcohol}

The MA by Pelucchi et al. [34] was considered most comprehensive and they found no statistically significant association for heavy drinkers $(\geq 3$ drinks ( $\geq 37.5 \mathrm{~g}) /$ day; RR 0.97; $95 \%$ CI 0.72-1.31; $\mathrm{n}=7$ ) or moderate drinkers (<3 drinks/day; RR 0.98; $95 \%$ CI 0.89-1.07; $\mathrm{n}=15$ ).

\section{Egg}

The MA by Li et al. [35] was the only MA identified in which no significant association was detected for overall egg consumption (RR 1.11; $95 \%$ CI 0.73-1.69; $n=6$ ). However, when looking at cooking methods, an increased risk of bladder cancer was found for fried egg (RR 2.04; $95 \%$ CI 1.41-2.95; n = 2) but not for boiled egg (RR $1.25 ; 95 \%$ CI $0.82-1.91 ; \mathrm{n}=2$ ).

\section{Vitamin A: body levels, intake, and supplementation}

The MA by Tang et al. [36] was selected as most comprehensive MA for both overall intake and body levels of vitamin A, and vitamin A supplementation. They found a significantly lower risk of bladder cancer among individuals with higher dietary intake or higher blood levels of vitamin A (RR 0.82; $95 \%$ CI 0.65-0.95; $\mathrm{I}^{2}=46.3 \%$; $\mathrm{n}=11$ ). When looking only at intake of vitamin $\mathrm{A}$, the association was significantly protective for vitamin A supplementation, consisting of beta-carotene, and/or retinol supplementation (highest vs. lowest: RR 0.64; $95 \%$ CI $0.47-0.82 ; \mathrm{I}^{2}=0 \%$ ) but not for dietary intake (highest vs. lowest: RR 0.90; $95 \%$ CI 0.80-1.01; $\mathrm{I}^{2}=0 \%$ ).

Jeon et al. [37] investigated the effect of only betacarotene supplementation (so not retinol), compared to no supplementation, and found an increased risk of bladder cancer (RR 1.52; $95 \%$ CI 1.03-2.24; $\mathrm{I}^{2}=0.0 \% ; \mathrm{n}=2$ ).

\section{Vitamin $C$}

The MA by Wang et al. [38] was the only MA studying the association between vitamin $\mathrm{C}$ intake and bladder cancer. Combining vitamin $\mathrm{C}$ intake from diet and supplementation, they found a marginally significantly decreased risk of bladder cancer (RR 0.90; $95 \%$ CI 0.79-1.00; $\mathrm{I}^{2}=43.7 \%$; $\mathrm{n}=20)$.

\section{Vitamin D}

The MA by Liao et al. [39] investigated only the role of vitamin D serum level. They found that the risk of bladder cancer was decreased among individuals with the highest levels of serum vitamin D (RR 0.75; $95 \%$ CI 0.65-0.87; $\mathrm{n}=5$ ). The MA by Chen et al. [40] reported on the role of vitamin $\mathrm{D}$ intake from diet and supplements. Combining vitamin D intake from diet and supplementation, they found no significantly altered risk of bladder cancer (RR 0.92; $95 \%$ CI 0.66-1.28; $\mathrm{n}=3$ ).

\section{Vitamin E}

The MA by Wang et al. [38] was selected as the most comprehensive MA and reported significantly reduced risk of bladder cancer for vitamin $\mathrm{E}$ intake (RR 0.82; $95 \% \mathrm{CI}$ $\left.0.74-0.90 ; \mathrm{I}^{2}=0 \% ; \mathrm{n}=15\right)$.

\section{Folate}

The association between folate intake and risk of bladder cancer was studied only in a MA by He et al. [41]. They found a significantly reduced risk of bladder cancer (RR 0.84; $95 \%$ CI 0.72-0.96; $\mathrm{I}^{2}=28.9 \% ; \mathrm{n}=13$ ). The association remained significantly reduced when pooling studies on dietary folate only (RR $0.82 ; 95 \%$ CI $\left.0.65-0.99 ; \mathrm{I}^{2}=57.9 \% ; \mathrm{n}=9\right)$, but not on supplemental folate only (RR $0.91 ; 95 \%$ CI $0.58-1.25 ; \mathrm{I}^{2}=62.6 \%$; $\mathrm{n}=3$ ).

\section{Selenium: body levels and supplementation}

Two MAs [42, 43] were identified studying the association between selenium levels in the body, measured in serum or toenail, and bladder cancer. Amaral et al. [42] was selected as the most comprehensive MA. They found that the risk of bladder cancer was significantly lower among individuals with the highest selenium levels in the body (RR 0.61; $95 \%$ CI 0.42-0.87; $\mathrm{n}=7$ ).

Selenium supplementation was studied in one MA by Vinceti et al. [43]. They meta-analysed two RCTs and found no statistically significant association (RR 1.14; $95 \%$ CI $0.81-1.61 ; \mathrm{n}=2$ ).

\section{Antioxidant supplementation}

One MA by Myung et al. [44] reported on multiple types of antioxidant supplementation together, studied in RCTs. They found that antioxidant supplementation significantly increased the risk of bladder cancer (RR 1.52; $95 \% \mathrm{CI}$ $\left.1.06-2.17 ; \mathrm{I}^{2}=0.0 \% ; \mathrm{n}=4\right)$. 


\section{Dietary acrylamide}

The association between dietary acrylamide intake and bladder cancer was studied in one MA, authored by Pelucchi et al. [45] They reported no statistically significant association (RR $0.93 ; 95 \%$ CI $0.78-1.11 ; \mathrm{n}=3$ ).

\section{Obesity}

Two MAs [46, 47] reported on the association between body weight and bladder cancer. The MA by Sun et al. [46] was selected as most comprehensive. They found an increased risk of bladder cancer among obese individuals (BMI $\geq 30 ;$ RR $1.10 ; 95 \%$ CI $1.03-1.18 ; \mathrm{I}^{2}=8.8 \%$; $\mathrm{n}=12$ ) but not among pre-obese individuals (BMI 25.00-29.99; RR 1.07; $95 \%$ CI 0.99-1.16; $\mathrm{I}^{2}=46.1 \%$; $\mathrm{n}=13)$.

\section{Consumption of tobacco}

Active smoking Eight MAs [10, 11, 48-53] were identified on the effect of active smoking of tobacco on the risk of bladder cancer. With regard to cigarette smoking, Cumberbatch et al. [53] and Van Osch et al. [10] both included almost the same number of primary studies: $\mathrm{n}=90$ versus $\mathrm{n}=89$ respectively. Although theoretically this meant that the paper by Cumberbatch et al. would be most comprehensive, after discussion between the authors, the paper by Van Osch et al. was selected as most comprehensive as they reported dose-response analyses on duration, intensity, and time since cessation of smoking. Because smoking was already known to be the most important modifiable risk factor of bladder cancer, the dose-response variables were considered valuable additional information. It must be noted that calculated risks do not differ much between both MAs (Appendix 2).

Van Osch et al. [10] reported a significantly increased risk of more than 3 times in current smokers (RR 3.14; $95 \%$ CI 2.53-3.75) and almost 2 times in former smokers (RR 1.83; $95 \%$ CI 1.52-2.14). Their dose-response associations showed a positive trend with increasing intensity of smoking and number of pack years, reaching a plateau from about 15 cigarettes/day and 50 pack-years. Increasing duration since cessation of smoking resulted in a reducing risk, although former smokers remained at a $50 \%$ increased risk even after more than 20 years of cessation.

Hemelt et al. [11] also reported on the risk among smokers of any type of tobacco. They found an increased incidence of bladder cancer among current smokers (RR 3.35 ; $95 \%$ CI $2.90-3.88 ; \mathrm{n}=11$ ) as well as among eversmokers (RR 2.25; $95 \%$ CI 1.96-2.59; $\mathrm{n}=15$ ).

Two MAs [52,53] additionally reported on the effect of pure cigar and pure pipe smoking. Pitard et al. [52] was considered most comprehensive and they reported a significantly increased risk of bladder cancer among both pipe smokers (RR 1.9; $95 \%$ CI $1.2-3.1 ; \mathrm{n}=6$ ) and cigar smokers (RR 2.3; $95 \%$ CI 1.6-3.5; $\mathrm{n}=6$ ).

Passive smoking Van Hemelrijck et al. [54] reported on the association between passive smoking and bladder cancer. They found no statistically significant association in individuals exposed to passive smoking (RR 0.99; $95 \%$ CI $0.86-1.14 ; \mathrm{I}^{2}=35.6 \% ; \mathrm{n}=8$ ) compared to neversmoking individuals with no exposure to passive smoking.

Smokeless tobacco Use of smokeless tobacco, including chewing tobacco, oral snuff, and unspecified smokeless tobacco, was studied in two MAs [53, 55]. Lee et al. [55] was considered most comprehensive. No statistically significant association was found with development of bladder cancer (RR 0.95; $95 \%$ CI 0.71-1.29; $\mathrm{n}=9$ ).

\section{Physical activity}

Keimling et al. [56] wrote the only MA on the association between physical activity and bladder cancer. They found a statistically significant protective effect on the bladder cancer risk among individuals with the highest levels of physical activity (RR 0.86 ; $95 \%$ CI $0.77-0.95 ; \mathrm{n}=7$ ).

\section{Personal hair dye use}

Turati et al. [57] updated previous MAs [58-60] to investigate the association between personal use of hair dye and bladder cancer. They found no statistically significant increased risk among users of personal hair dye (smoking adjusted RR 0.94; $95 \%$ CI $0.82-1.08 ; \mathrm{n}=12$ ).

\section{Occupational factors}

Multiple MAs were identified on the association between occupational factors and bladder cancer. Most MAs reported on a single occupation or occupational group, or a single specific occupational exposure (Appendix 2). Moreover, four MAs [61-64] reported on a large number of occupational categories. Cumberbatch et al. [61] and Reulen et al. [62] authored two large MAs on different occupations based on 217 and 130 different studies respectively, whereas Kogevinas et al. [63] and 't Mannetje et al. [64] both did a pooled analysis of eleven case-control studies conducted in European countries reporting results for men and women, respectively. The paper by Cumberbatch et al. was considered the most comprehensive for all identified occupations based on the number of studies included. They found the following occupations to have a statistically significant increased risk of more than $20 \%$ : 
tobacco workers, dye workers, chimney sweeps, nurses, rubber workers, waiters, aluminium workers, hairdressers, printers, seamen, oil and petroleum workers, shoe and leather workers, and plumbers. Protective effects were found for farmers, gardeners, teachers, forestry workers, religious and legal workers, and economically inactive workers. Statistically significant associations reported by Cumberbatch et al. are listed in Table 1. All other associations are summarized in Appendix 3 along with findings by Reulen et al. [62], Kogevinas et al. [63], and 't Mannetje et al. [64].

\section{Probability of causation}

The estimates for probability of causation (POC), displayed in percentages, are presented in Table 1 . The percentages ranged from 9 to $68 \%$ among the lifestyle factors, and between 4 and $42 \%$ for the occupational exposures. The four highest POCs are found among the smoking estimates: $68 \%$ of the bladder cancer incidence among cigarette smokers, $57 \%$ among cigar smokers, $47 \%$ among pipe smokers and $45 \%$ among former cigarette smokers can be attributed to this habit.

A POC was calculated for four factors combined, which were considered sufficiently independent: total fruit and vegetable consumption, processed meat consumption, smoking, and physical activity. To avoid overlap, the only estimate included for smoking was for cigarette smoking as most smokers are (also) cigarette smokers $(78.7 \%)$ and only $4.5 \%$ was found to be pure pipe and/or cigar smoker [52]. The combined POC showed that up to $81.8 \%$ of the bladder cancer cases, among those with non-optimal lifestyle behaviours, could be prevented through lifestyle modifications.

\section{Discussion}

In total, 12 lifestyle factors and 48 occupational factors emerged that significantly increased or decreased the risk of bladder cancer. Such numerous modifiable risk factors present an opportunity and great potential for prevention. Below, the significantly associated risk factors will be discussed.

\section{Smoking}

The most important risk factor proved to be smoking, particularly the risk was highest for current smokers of cigarettes (RR 3.14), [10] but also for smokers of cigars only (RR 2.3) and pipes only (RR 1.9) [52]. An interesting finding was that a plateau was reached at about 15 cigarettes/day, meaning that heavier smoking does not carry a much higher risk than less heavy smoking [10]. Although the risk slowly decreased with longer cessation of cigarette smoking, the RR was still $50 \%$ increased 20 years of cessation.

Characteristics of the tobacco smoked may influence this association. In previous studies, individuals smoking black tobacco had a higher risk compared to smokers of blond tobacco, due to the higher concentrations of carcinogens in black tobacco [65-71]. Also, inhalation of the tobacco smoke into the lungs and throat resulted in a higher risk compared to inhalation only into the mouth, $[49,65$, 71-76] although not all evidence supports this [77-80].

Tobacco smoke contains numerous carcinogens that contribute to the initiation and promotion of tumour development. These chemicals are renally excreted, making it directly toxic to the human urinary bladder. During metabolisation of these compounds, DNA-adducts are formed, leading to permanent genetic mutations. If this occurs in an oncogene or tumour suppressor gene, it may result in uncontrolled growth and eventually cancer.

Genetic mutations, such as NAT2 slow acetylation and GSTM null genotypes, have previously been shown to be associated with increased susceptibility to cancer [3]. The enzymes for which the genes code play a role in the detoxification pathways of i.a. aromatic amines and PAHs. These mutations do not intrinsically cause bladder cancer but do increase susceptibility when exposed to tobacco smoke or other sources of exposure [81, 82].

\section{Dietary factors}

Because the metabolites of many food groups are excreted by the urinary tract, dietary factors have often been suggested and researched as risk factors of bladder cancer [83]. Several different nutritional factors have been identified, showing both increased and decreased risks of bladder cancer.

Fruit, vegetables, and antioxidants

One key group of foods that was associated with a lower risk of bladder cancer were fruits and vegetables. Besides these groups as a whole, intake of both citrus fruit and cruciferous vegetables were researched. The effect is suggested to be due to the vitamins, minerals, and phytochemicals that fruit and vegetables contain, which have antioxidant properties [84, 85]. Antioxidants may protect against cancer through inhibition of oxidation of DNA, 
controlling of cell proliferation and apoptosis [85], and facilitation of metabolisation of carcinogenic compounds into less toxic substances, although the association may be dose-dependent [86].

It should be noted that significant publication bias was found in the MA on overall and citrus fruit consumption [19]. Because small studies with negative results tend not to be published, the effect size found in the MAs on these risk factors may actually be attenuated.

The MAs included in our review that studied vitamins separately, came to supporting conclusions. For all but vitamin $\mathrm{C}$, higher intakes were associated with a significantly reduced risk of bladder cancer, with effects on $-39 \%$ for selenium, $-18 \%$ for vitamin $\mathrm{A}$ and $\mathrm{E}$, and $-16 \%$ for folate.

Vitamin A intake was found to be negatively associated with bladder cancer when data on dietary intake, supplementation, and blood levels were combined. However, when studied by intake source separately, the protective effect was only found for vitamin A supplementation but not for dietary intake [36]. Furthermore results on supplementation were not consistent as Jeon et al. [37], found a significantly increased risk of bladder cancer of $52 \%$ among participants taking supplementation in experimental studies. These conflicting results may be the result of a dose-dependent relationship, showing intake to be protective at low doses and harmful at high doses. Another explanation may be the different study design, in which the reduced risk found in observational studies may actually be the effect of an overall healthier lifestyle, as those individuals who choose to use nutritional supplementation tend to have a healthier lifestyle overall [87], Vitamin A plays an important role in cell proliferation and differentiation [88], and carotenoids can directly affect carcinogenesis through their antioxidant properties, or indirectly after transformation of provitamin A carotenoids into vitamin A $[89,90]$.

Vitamin E consists of a group of lipid soluble molecules, including four tocopherols and four tocotrienols. Specifically $\gamma$-tocopherol, $\delta$-tocopherol, and tocotrienols inhibit several inflammatory pathways, [91] which is important because chronic inflammation or chronic infection influences development and progression of cancer, [92] In addition, vitamin $\mathrm{E}$ is a potent lipid-soluble antioxidant, inhibiting lipid peroxidation and thereby protecting cell membranes from peroxidative damage [93].

Although higher levels of selenium protected against bladder cancer, causation could not be confirmed through supplementation intervention [42], The specific mechanism of action of selenium in carcinogenesis is not yet well understood. Several theories have been suggested, including selenoproteins serving as antioxidants and metabolites of selenium involved in redox cycling, modification of protein thiols, and methionine mimicry [94].

However, despite these suggested protective properties of antioxidants, analysis of multiple types of antioxidant supplementation together, showed a $52 \%$ increased risk of bladder cancer [44]. An explanation for this discrepancy may be that it is not one antioxidant alone that has cancerpreventative properties, but rather the interaction between multiple antioxidants and other phytochemicals, such as it occurs with consumption of a diet rich in fruit and vegetables.

\section{Other nutrients and food groups}

Because consumption of processed meat but not red meat was associated with bladder cancer, the effect may result from different forms of mechanical, chemical, and enzymatic treatment that processed meat has been exposed to. One hypothesis suggests that nitrite, which is used as a colour and flavour preservative in processed meat, combines with secondary amines from proteins to form nitrosamines that are found to be carcinogenic to, amongst other organs, the bladder [95]. Although red and processed meat are often studied in relation to disease development, particularly cancer, the exact mechanism of action is still unclear and is likely to be a combination of factors present in or associated with meat consumption $[96,97]$.

The protective effect of folate, a vitamin predominantly found in vegetables, is suggested to be through its role in DNA synthesis, repair, and methylation [98]. In previous research, low levels of folate were associated with hypomethylation of DNA resulting in dysregulation of proto-oncogenes and tumour suppressor genes, and therefore an increased risk of cancer [99]. However, the association is not as straightforward as may be expected. Research suggests that timing and dose of folate plays an important role in its effect on cancer development [100]. Because folate plays a role in de-novo synthesis of nucleotides, it will support healthy tissue and prevent tumour development. However, once pre-neoplastic lesions have been established, it will also support these rapidly proliferating tissues resulting in rapid tumour progression.

In line with previous findings for colorectal cancer [101] and breast cancer, [102] higher serum vitamin D was found to be protective against bladder cancer. Calcitriol, the potent hormone produced in the body from vitamin D, plays a role in multiple stages of cancer development, through both genomic and non-genomic pathways [103]. 
No association was found for dietary and supplemental intake of vitamin $\mathrm{D}$, which may result from dietary intakes not adequately reflecting calcitriol available to the body as it is also endogenously formed in response to UV-light.

Previous reviews have also mentioned other dietary factors increasing the risk of bladder cancer, among which higher intake of soy, fat, barbecued meats, and artificial sweeteners [84, 104]. However, no MAs were identified on these factors so these factors have not been included in our overview.

\section{Fluid intake and water contaminants}

Whereas increased intake of fluids dilutes urine and increases micturition, leading to a reduced exposure of the bladder to carcinogens, it may also increase exposure when the fluid itself contains carcinogens [3]. For example, increased risk of bladder cancer was found with water chlorination [105, 106] and arsenic contamination [107, 108]. However, no significant association was found for either all fluid intake or water specifically [22]. Together, this is in line with the suggested dual effect of increased fluid intake on bladder cancer risk.

\section{Physical activity}

Physical activity was found to have a small but significant protective effect against bladder cancer. The effect found was not modified by BMI or smoking, as the authors explain in their MA [56]. Although the exact mechanism through which physical activity protects against cancer is not yet known, several mechanisms have been suggested acting on both tumour initiation and progression. These potential mechanisms include modification of carcinogen activity, and enhancement of antioxidant and DNA repair processes [109].

\section{Occupation and occupational exposure to chemicals}

Occupational factors are considered the second most important risk factor for bladder cancer after smoking [3, 110]. Over the years, many carcinogens have been identified by the IARC as definitely (group 1) or probably carcinogenic (group 2a). Occupational exposure to these carcinogens has been largely controlled and workers are now exposed to weaker carcinogens. The results of the MA by Cumberbatch et al. [53] show multiple occupations or occupational exposures that are significantly associated with the risk of bladder cancer.

Particularly workers exposed to aromatic amines, PAH, tobacco and tobacco smoke, combustion products, and heavy metals are at an increased risk. However, these findings will not be further discussed and repeated here as the MA by Cumberbatch et al. [61] offers an interesting and elaborate discussion on the matter. They also attempted to study a change in occupational risk over time but were limited by heterogeneity and small sample sizes.

Interestingly, farmers, gardeners, teachers, and forestry workers were found to be at a significantly lower risk. Farmers have been studied numerous times with regard to disease risk and have been suggested to be at both an increased and decreased risk of bladder cancer. It is thought of as a risk factor due to the exposure to chemicals such as pesticides, viruses, and other exposures. Although an increased risk was found in association with exposure to some pesticides, the evidence is not conclusive [111]. Both the European Food Safety Authority (EFSA) [112] and the IARC [113] did not find sufficient evidence to support carcinogenicity of pesticides. On the other hand, farmers, and possibly also gardeners and forestry workers, often have higher physical activity levels and fruit and vegetable consumption, as well as a lower prevalence of smoking [111].

Finally, in addition to exposure to carcinogens on an occupational basis, an increased risk of bladder cancer in certain occupational groups may also be the result of fewer possibilities for micturition during working hours. This may apply to, for example, sales workers, professional drivers, or other occupations where bathroom visits are limited to break times.

\section{Public health impact}

The calculated POCs show that by adopting the right lifestyle, while considering harmful environmental and occupational exposures, a large proportion of the burden of bladder cancer could be prevented. Particularly for smoking the POC was high, highlighting that smoking cessation and prevention of smoking initiation should remain high on the agenda. In addition, a diet rich in fruit and vegetables, particularly citrus fruit and cruciferous vegetables, and low in processed meat should be stimulated. Particularly working conditions involving exposure to aromatic amines, PAHs, tobacco and tobacco smoke, combustion products, and heavy metals should be given priority to reduce exposure to these compounds.

\section{Limitations}

The quality of a MA is strongly determined by the quality of the primary studies included. Not all studies corrected 
for smoking status, which is the most important risk factor for bladder cancer. The effects of this may be large, leading to an under- or overestimation of the true effect size. To minimise the effect of confounding in our study, only the most adjusted estimates from each MA were selected. Selection of the most comprehensive publication was based on the largest number of primary studies included, rather than the largest sample size. The latter would have been more desirable as the power of a study depends on it, but this data was often unavailable in the publications and number of studies included had to be used as a proxy. Results of MMA could be affected by duplicate inclusion of primary studies, leading to inflated precision and homogeneity [114]. Therefore, we minimised duplicate inclusion and performed a MMA only if at least $50 \%$ of the included primary studies were 'new' in subsequent MAs.

The main limitation with regard to the combined POC is assumption of independence of risk factors. It is well known that lifestyle behaviours tend to cluster, [115] indicating that the factors are unlikely to be fully independent. Therefore, the combined POC is likely to be an overestimation and should be considered a maximum. However, the POCs of each of the individual factors are substantial, indicating that each plays an important part in the risk.

In this study, estimates of bladder cancer incidence were given priority over estimates of prevalence or mortality. Although the majority of included studies specified the outcome measure that was included or provided stratified results, not all did (Table 1). Because mortality and prevalence figures are greatly influenced by treatment success, this may have influence the estimates obtained.

Heterogeneity may always be an issue in MAs. Several of the studies included in the current review show moderate to high levels of heterogeneity. Whereas some identified study design, gender, or geographical region as possible source of heterogeneity [19, 22, 31], others could not find an explanation [20].

It should be noted that different classification criteria may be applied in studies to determine cases, including the TNM classification and stage grouping. Because any effect would be unlikely and small, this potential difference was not taken into consideration when selecting estimates.

This publication is a review of MAs. Additional risk factors for which no MA is available may prove to be of importance, but have not been included in this review. This study will help to identify gaps in knowledge with regard to MAs available.

It was our responsibility to give an objective and complete overview of the literature available. By using a protocol, including only MAs and by dealing appropriately with unexpected issues, we believe to have provided an overview of the risk factors associated with bladder cancer with high levels of objectivity and reliability.

In conclusion, the burden of bladder cancer could be significantly reduced through modification of lifestyle, environment, and occupational exposures. In fact, having numerous modifiable risk factors, among which multiple with a substantial RR, makes bladder cancer one of the most preventable diseases. Although substantial risks were found for, for example, smoking, some identified risk factors 'only' led to an increase or decrease of 10-15\%. This could be considered a minor effect, but reducing prevalence of a number of smaller risk factors together, could still result in significant overall risk reductions in the general population. Theoretically the included risk factors are, at least partially, modifiable. However, actually changing them is not always easily achieved, neither for one individual, let alone on a population level. Therefore, it is important that preventative and protective strategies pay attention to behaviour change in order to capture the greatest potential of risk reduction. When change is achieved, impact will not remain restricted to an improvement in the incidence of bladder cancer, as most of the included risk factors also play a role the risk of multiple other chronic diseases such as cancer or cardiovascular diseases, [116-118] and deaths [119]. Since relapse of bladder cancer is common, future research may also elucidate whether the same risk factors play a role in prevention of bladder cancer relapse as they do in incidence.

Acknowledgments This project was funded by the Maastricht University Interfaculty Programme 'Eatwell'. The funder had no influence in the development and execution of this systematic review.

\section{Compliance with ethical standards}

Conflict of interest The authors declare that they have no conflict of interest.

Open Access This article is distributed under the terms of the Creative Commons Attribution 4.0 International License (http://crea tivecommons.org/licenses/by/4.0/), which permits unrestricted use, distribution, and reproduction in any medium, provided you give appropriate credit to the original author(s) and the source, provide a link to the Creative Commons license, and indicate if changes were made.

\section{Appendix 1}

See Table 2. 
Table 2 List of meta-analyses identified for modifiable risk factors of bladder cancer

\begin{tabular}{|c|c|c|c|c|}
\hline Risk factor & Identified meta-analyses & Included & Included for? & Reason exclusion \\
\hline \multicolumn{5}{|l|}{ Diet } \\
\hline \multirow[t]{11}{*}{ Fruit and vegetables } & Riboli and Norat [120] & No & & $\begin{array}{l}\text { All primary studies are included in Yao } \\
\text { et al. [19] }\end{array}$ \\
\hline & Liu et al. [121] & No & & $>50 \%$ overlap \\
\hline & Vieira et al. [122] & No & & $>50 \%$ overlap \\
\hline & Liu et al. [123] & No & & $>50 \%$ overlap \\
\hline & Xu et al. [124] & No & & $>50 \%$ overlap \\
\hline & Steinmaus et al. [21] & Yes & Vegetables (MMA) & \\
\hline & Yao et al. [19] & Yes & Fruit and vegetables & \\
\hline & & & Fruit & \\
\hline & & & Vegetables (MMA) & \\
\hline & & & Cruciferous vegetables & \\
\hline & Liang et al. [20] & Yes & Citrus fruit & \\
\hline \multirow[t]{6}{*}{ Tea } & Zeegers et al. [125] & No & & Include other urinary tract cancer \\
\hline & Zhang et al. [126] & No & & $>50 \%$ overlap \\
\hline & Wu et al. [127] & No & & $>50 \%$ overlap \\
\hline & Wang et al. [128] & No & & $>50 \%$ overlap \\
\hline & Boehm et al. [129] & No & & Not MA \\
\hline & Qin et al. [130] & Yes & Tea & \\
\hline \multirow[t]{8}{*}{ Coffee } & Arab [131] & No & & Not MA \\
\hline & Pelucchi et al. [132] & No & & Not MA \\
\hline & Huang et al. [24] & No & & $>50 \%$ overlap \\
\hline & Sala et al. [28] & No & & $>50 \%$ overlap \\
\hline & Zhou et al. [25] & No & & $>50 \%$ overlap \\
\hline & Villanueva et al. [27] & Yes & Coffee (MMA) & \\
\hline & Yu et al. [26] & Yes & Coffee (MMA) & \\
\hline & Wu et al. [29] & Yes & Coffee (MMA) & \\
\hline \multirow[t]{2}{*}{ Beverage consumption } & Zeegers et al. [6] & No & & Not MA \\
\hline & Boyle et al. [30] & Yes & Sweetened carbonated beverages & \\
\hline \multirow[t]{4}{*}{ Milk } & Zhang et al. [133] & No & & Not MA \\
\hline & Lampe [134] & No & & Not MA \\
\hline & Mao et al. [31] & No & & $>50 \%$ overlap \\
\hline & Li et al. [135] & Yes & Milk & \\
\hline Fish & $\mathrm{Li}$ et al. [32] & Yes & Fish & \\
\hline \multirow[t]{3}{*}{ Meat } & Wang and Jiang [136] & No & & Include urothelial cancer \\
\hline & Steinmaus et al. [21] & No & & \\
\hline & Li et al. [33] & Yes & Meat & \\
\hline \multirow[t]{5}{*}{ Alcohol } & Mao et al. [137] & No & & Include urothelial cancer \\
\hline & de Menezes et al. 138] & No & & Not MA \\
\hline & Bagnardi et al. [139] & No & & $>50 \%$ overlap \\
\hline & Zeegers et al. [140] & No & & $>50 \%$ overlap \\
\hline & Pelucchi et al. [34] & Yes & Alcohol & \\
\hline \multirow[t]{2}{*}{ Egg } & Fang et al. [141] & No & & Include urothelial cancer \\
\hline & Li et al. [35] & Yes & Egg & \\
\hline Dietary acrylamide & Pelucchi et al. [34] & Yes & Dietary acrylamide & \\
\hline \multirow[t]{2}{*}{ Vitamin A } & Tang et al. [36] & Yes & Vitamin A & \\
\hline & Steinmaus et al. [21] & No & & \\
\hline \multirow[t]{2}{*}{ Vitamin D } & Liao et al. [39] & Yes & Serum level & \\
\hline & Chen et al. [40] & Yes & Diet and supplement & \\
\hline \multirow[t]{2}{*}{ Vitamin C \& E } & Wang et al. [38] & Yes & Vitamin C & \\
\hline & & & Vitamin E & \\
\hline
\end{tabular}


Table 2 continued

\begin{tabular}{|c|c|c|c|c|}
\hline Risk factor & Identified meta-analyses & Included & Included for? & Reason exclusion \\
\hline & Chen et al. [40] & & & $>50 \%$ overlap \\
\hline Folate intake & He and Shui $[41]$ & Yes & Folate & \\
\hline \multirow{4}{*}{$\begin{array}{l}\text { Beta carotene supplement, Antioxidant } \\
\text { supplement }\end{array}$} & Musa-Veloso et al. [142] & No & & No MA for bladder cancer \\
\hline & Coulter et al. [143] & No & & No MA for bladder cancer \\
\hline & Jeon et al. [37] & Yes & $\begin{array}{l}\text { Beta-carotene } \\
\text { supplements }\end{array}$ & \\
\hline & Myung et al. [44] & Yes & Antioxidant supplement & \\
\hline \multirow[t]{2}{*}{ Selenium } & Amaral et al. [42] & Yes & $\begin{array}{l}\text { Selenium levels in the } \\
\text { body }\end{array}$ & \\
\hline & Vinceti et al. [43] & Yes & Selenium supplementation & \\
\hline Omega-3 fatty acids & MacLean et al. [144] & No & & No MA for bladder cancer \\
\hline Zinc, Copper & Mao et al. [145] & No & & No risk estimates reported \\
\hline Olive oil & Psaltopoulou et al. [146] & No & & No MA for bladder cancer \\
\hline \multirow[t]{5}{*}{ Fluid intake } & Lotan et al. [147] & No & & No MA \\
\hline & Stelmach and Clasen [148] & No & & No MA \\
\hline & Villanueva et al. [27] & No & & Included in Bai et al. [22] \\
\hline & Isa (submitted) & No & & $>50 \%$ overlap \\
\hline & Bai et al. [22] & Yes & Total fluid intake & \\
\hline \multirow[t]{2}{*}{ Obesity } & Qin et al. [47] & No & & $>50 \%$ overlap \\
\hline & Sun et al. [46] & Yes & Obesity & \\
\hline \multicolumn{5}{|l|}{ Behaviours } \\
\hline \multirow[t]{14}{*}{ Smoking } & Zeegers et al. [149] & No & & Include other urinary tract cancer \\
\hline & Crivelli et al. [150] & No & & $\begin{array}{l}\text { Effect of smoking on prognosis of } \\
\text { bladder cancer patients }\end{array}$ \\
\hline & Sasco et al. [151] & No & & No MA \\
\hline & Zeegers et al. [6] & No & & No MA \\
\hline & Vineis et al. [152] & No & & No MA \\
\hline & Shiels et al. [153] & No & & Not primary prevention of $\mathrm{BC}$ \\
\hline & 't Mannetje et al. [154] & No & & $\begin{array}{l}\text { Discussed whether adjusting for } \\
\text { smoking affects association between } \\
\text { BC and occupation }\end{array}$ \\
\hline & Freedman et al. [49] & No & & $>50 \%$ overlap \\
\hline & Brennan et al. [50] & No & & $>50 \%$ overlap \\
\hline & $\begin{array}{l}\text { Brennan et al. (Women) } \\
\text { [51] }\end{array}$ & No & & $>50 \%$ overlap \\
\hline & Hemelt et al. [11] & No & & $>50 \%$ overlap \\
\hline & Puente et al. [48] & No & & $>50 \%$ overlap \\
\hline & Cumberbatch et al. [53] & No & & $>50 \%$ overlap \\
\hline & Van Osch et al. [10] & Yes & Cigarette smoking & \\
\hline Cigar and pipe & Pitard et al. [52] & Yes & Cigar and pipe & \\
\hline Passive smoking & Van Hemelrijck et al. [54] & Yes & Passive smoking & \\
\hline Smokeless tobacco & Lee et al. [55] & Yes & Smokeless tobacco & \\
\hline Waterpipe tobacco smoking & Akl et al. [155] & No & $\begin{array}{l}\text { Waterpipe tobacco } \\
\text { smoking }\end{array}$ & No MA, reporting one CC study \\
\hline Physical activity & Keimling et al. [56] & Yes & Physical activity & \\
\hline \multicolumn{5}{|l|}{ Environmental } \\
\hline \multirow[t]{5}{*}{ Personal hair dyes use } & Kelsh et al. [58] & No & & $\begin{array}{l}\text { All primary studies were included by } \\
\text { Turati et al. [57] }\end{array}$ \\
\hline & Takkouche et al. [60] & No & & $\begin{array}{l}\text { All primary studies were included by } \\
\text { Turati et al. [57] }\end{array}$ \\
\hline & Huncharek et al. [59] & No & & $\begin{array}{l}\text { All primary studies were included by } \\
\text { Turati et al. [57] }\end{array}$ \\
\hline & Rollison et al. [156] & No & & No MA \\
\hline & Turati et al. [57] & Yes & Personal hair dyes use & \\
\hline
\end{tabular}


Table 2 continued

\begin{tabular}{|c|c|c|c|c|}
\hline Risk factor & Identified meta-analyses & Included & Included for? & Reason exclusion \\
\hline \multicolumn{5}{|l|}{ Occupational } \\
\hline Various occupations & Cumberbatch et al. [61] & Yes & Various occupations & \\
\hline Various occupations & Reulen et al. [62] & No & & Not the most comprehensive \\
\hline Various occupations & Kogevinas et al. [63] & No & & Not the most comprehensive \\
\hline Various occupations & 't Mannetje et al. [64] & No & & Not the most comprehensive \\
\hline \multirow[t]{4}{*}{ Painters } & Bosetti et al. [157] & No & & $\begin{array}{l}\text { All primary studies are included by } \\
\text { Bachand (2010) }\end{array}$ \\
\hline & Kogevinas et al. [63] & No & & $\begin{array}{l}\text { All primary studies are included by } \\
\text { Bosetti et al. [157] }\end{array}$ \\
\hline & Guha et al. [158] & No & & $>50 \%$ overlap \\
\hline & Bachand et al. [159] & No & & Not the most comprehensive \\
\hline \multirow[t]{4}{*}{ Hairdresser } & Kogevinas et al. [63] & No & & $\begin{array}{l}\text { All primary studies included by } \\
\text { Takkouche et al. [160] }\end{array}$ \\
\hline & 't Mannetje et al. [64] & No & & $\begin{array}{l}\text { All primary studies included by } \\
\text { Takkouche et al. [160] }\end{array}$ \\
\hline & Takkouche et al. [160] & No & & $>50 \%$ overlap \\
\hline & Harling et al. [161] & No & & Not the most comprehensive \\
\hline \multirow[t]{2}{*}{ Sales workers } & Kogevinas et al. [63] & No & & included in't Mannetje et al. [160] \\
\hline & Mannetje et al. [162] & No & & $>50 \%$ overlap \\
\hline \multirow[t]{3}{*}{ Motor vehicle driving } & Kogevinas et al. [63] & No & & Included in Manju, 2009 \\
\hline & $\begin{array}{l}\text { Boffetta and Silverman } \\
\text { [163] }\end{array}$ & No & & $>50 \%$ overlap \\
\hline & Manju et al. [164] & No & & Not the most comprehensive \\
\hline Farmers & Acquavella et al. [165] & No & & Not the most comprehensive \\
\hline Foundry workers & Gaertner RR, 2002 [166] & No & & Not the most comprehensive \\
\hline Textile workers & Mastrangelo et al. [167] & No & & Not the most comprehensive \\
\hline \multirow[t]{2}{*}{ Flight attendants } & Tokumaru et al. [168] & No & & $>50 \%$ overlap \\
\hline & Buja et al. [169] & No & & \\
\hline \multirow[t]{2}{*}{ Petroleum industry } & Wong et al. [170] & No & & Mortality estimate only \\
\hline & Baena et al. [171] & No & & Not the most comprehensive \\
\hline Chemical workers & Greenberg et al. [172] & No & & Not the most comprehensive \\
\hline Dry cleaning & Vlaanderen et al. [173] & No & & Not the most comprehensive \\
\hline Inorganic lead compounds & Fu et al. [174] & No & & Not the most comprehensive \\
\hline \multirow[t]{2}{*}{ Acrylonitrile workers } & Cole et al. [175] & No & & Included genitourinary cancers \\
\hline & $\begin{array}{l}\text { Collins and Acquavella } \\
\text { [176] }\end{array}$ & No & & Not the most comprehensive \\
\hline \multirow[t]{3}{*}{ Polycyclic aromatic hydrocarbons } & Bosetti et al. [177] & No & & Updated in Rota et al. [179] \\
\hline & Boffetta et al. [178] & No & & No MA \\
\hline & Rota et al. [179] & No & & Not the most comprehensive \\
\hline Metalworking fluids & Calvert et al. [180] & No & & No MA \\
\hline Perchloroethylene (Dry cleaning) & Mundt et al. [181] & No & & No MA \\
\hline Asbestos-exposed workers & Goodman et al. [182] & No & & Mortality estimate only \\
\hline
\end{tabular}

$C C$ case-control, $M A$ meta-analysis, $O R$ odds ratio

\section{Appendix 2}

See Table 3. 


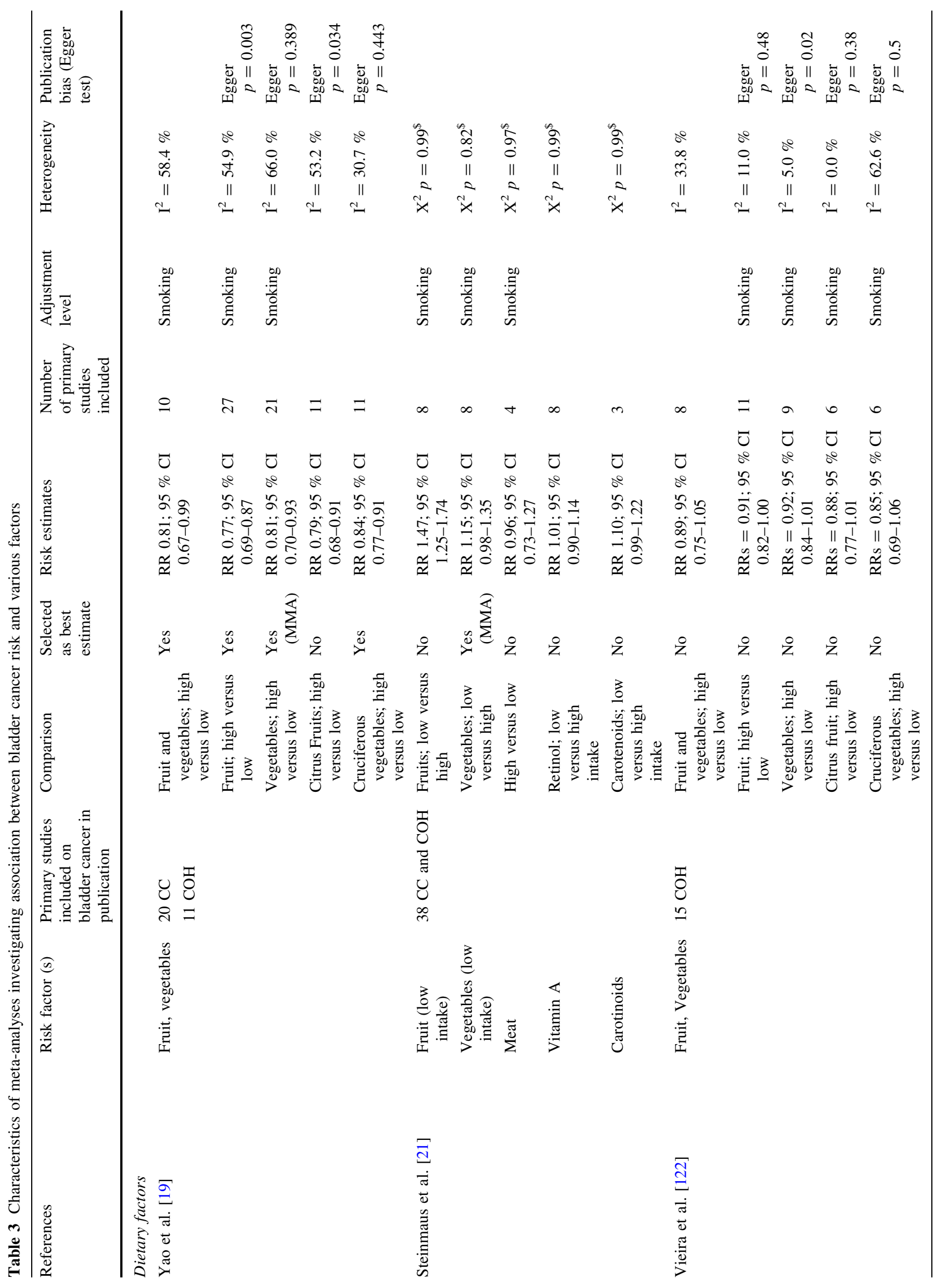




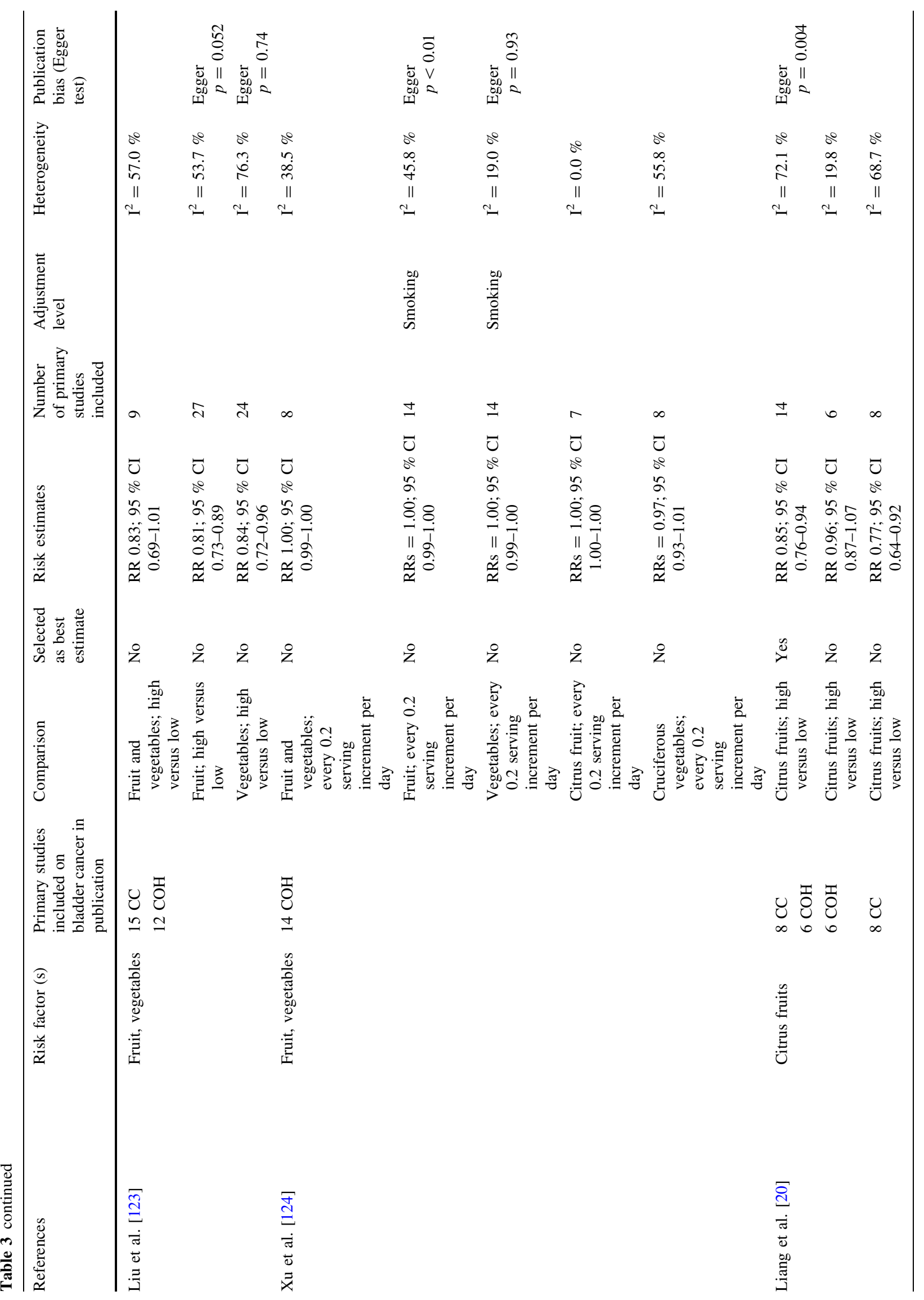




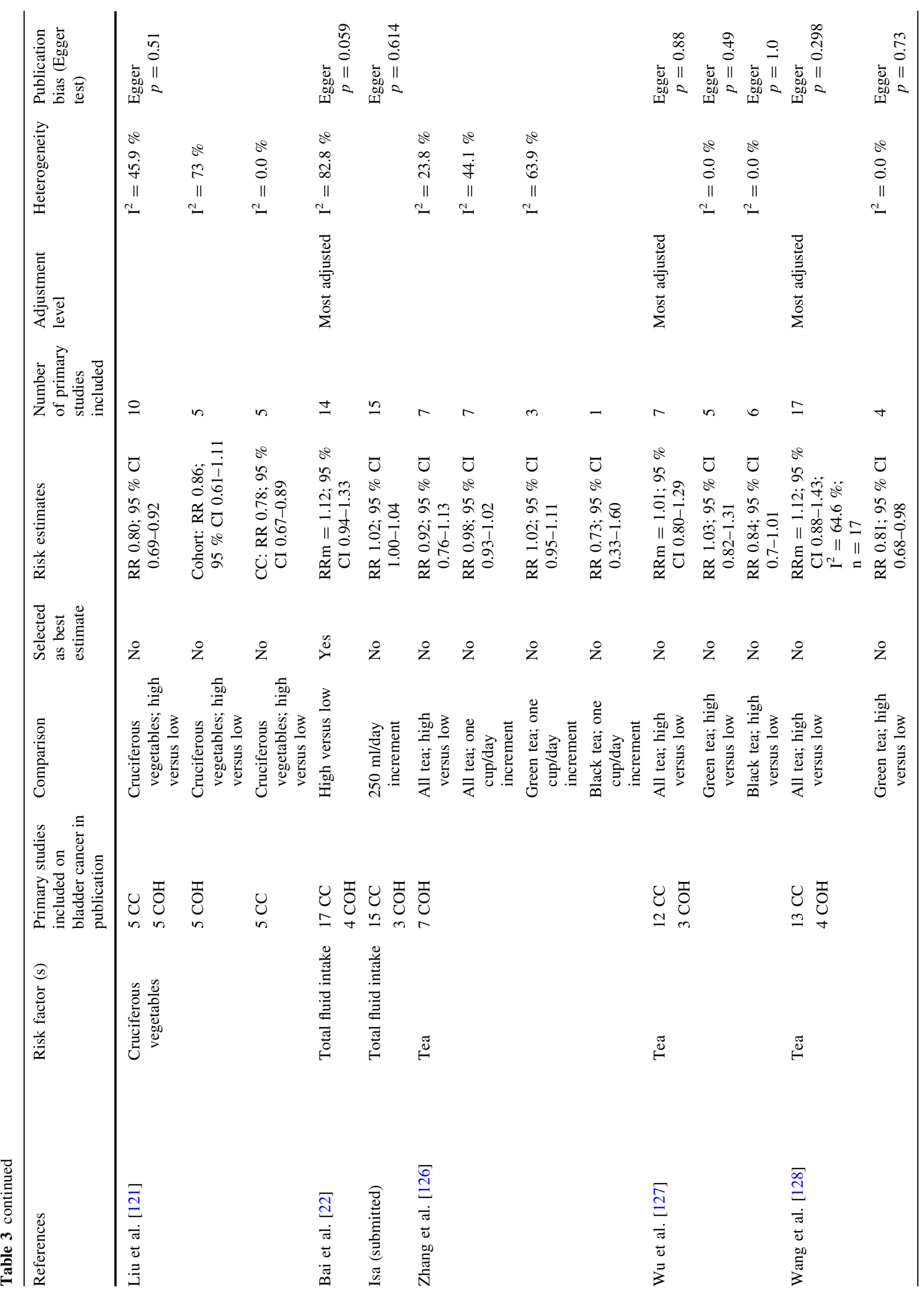




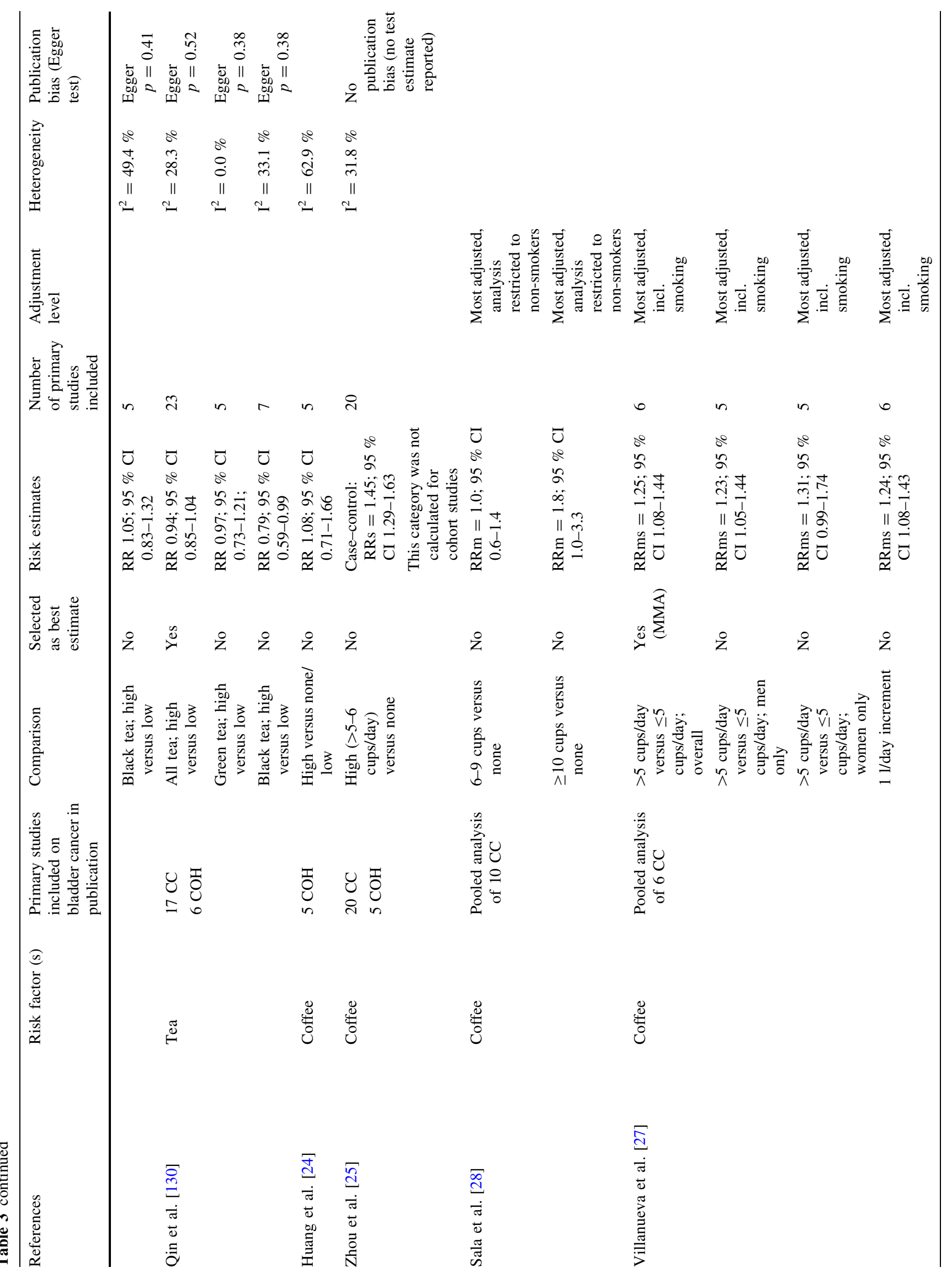




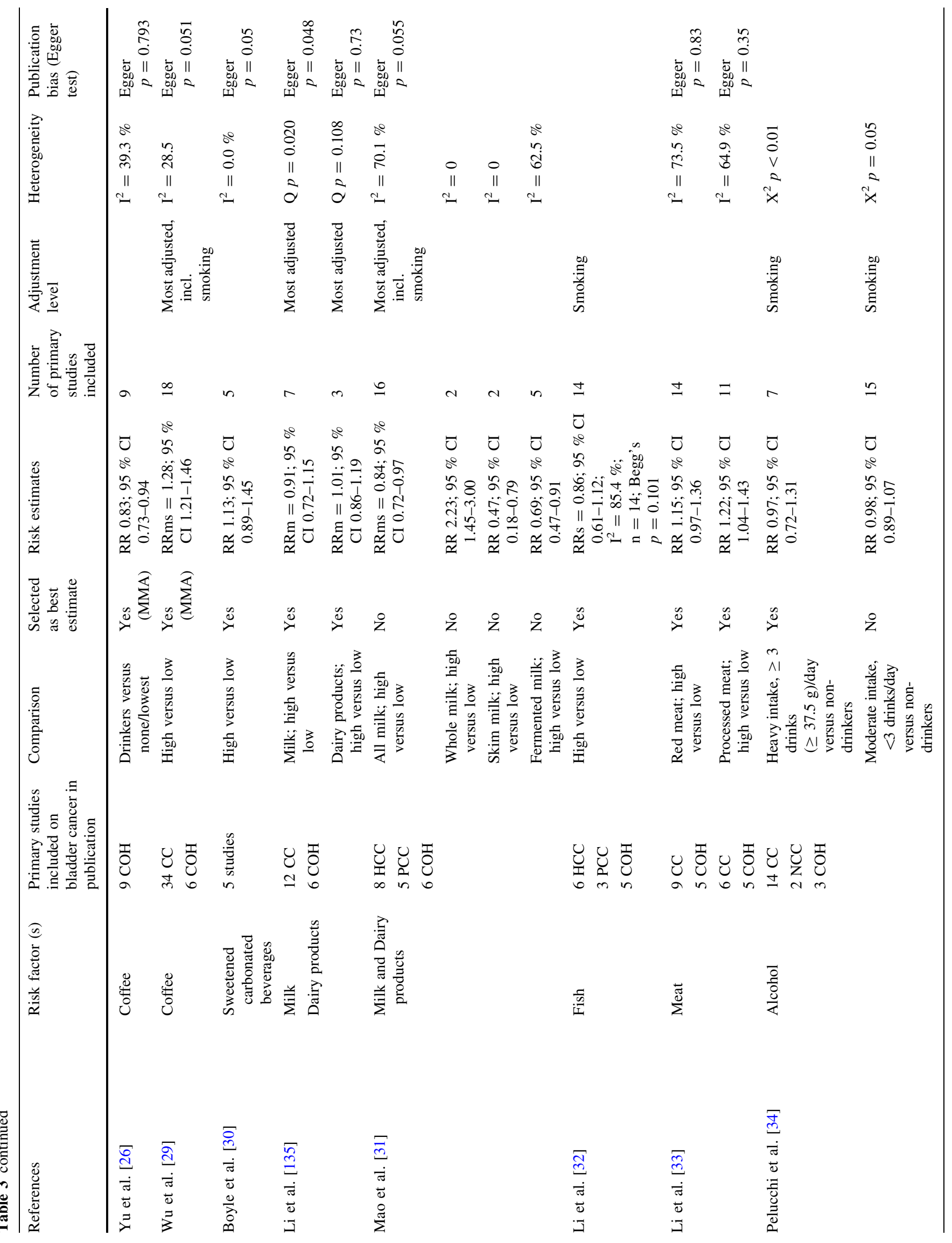




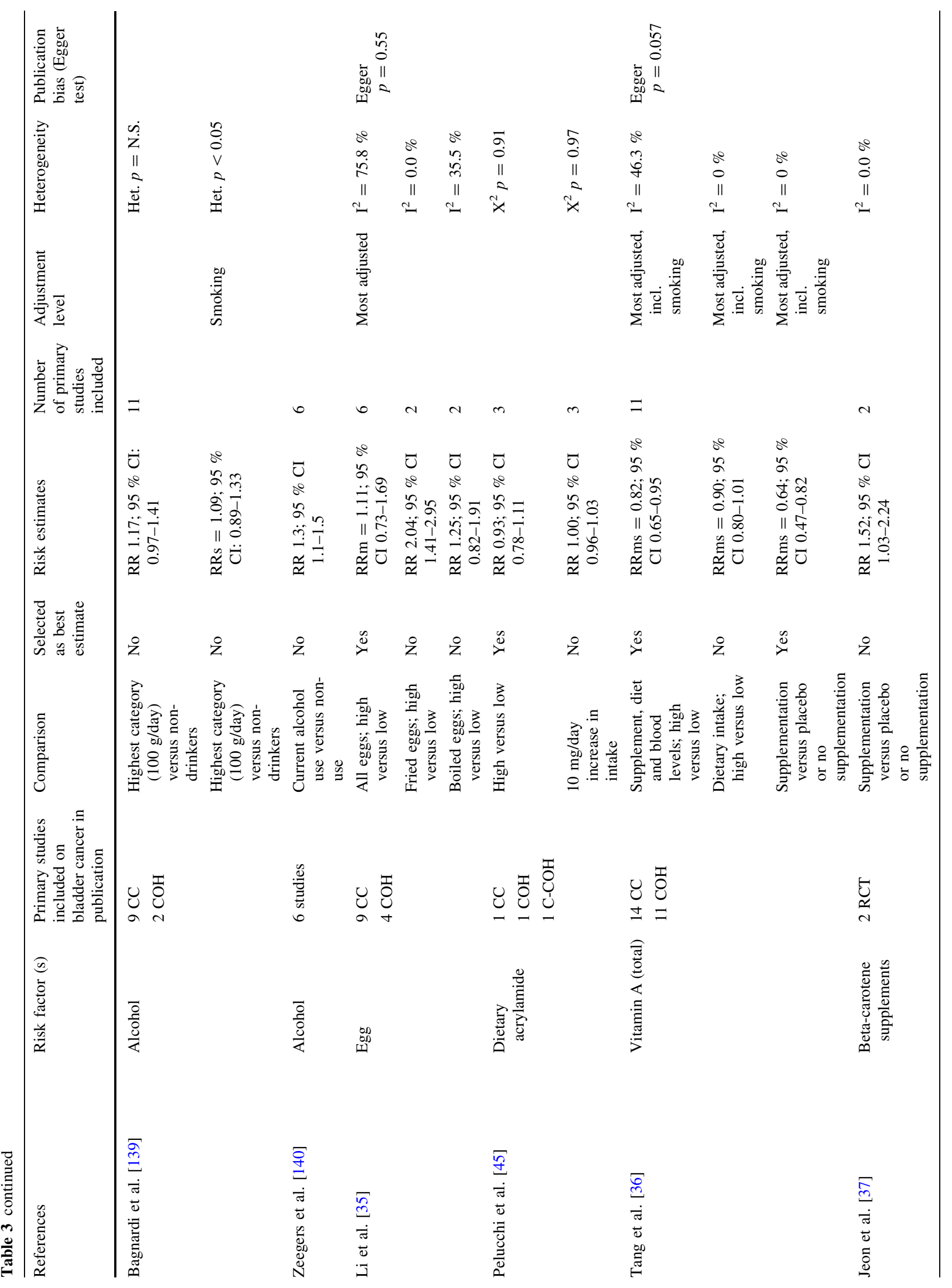




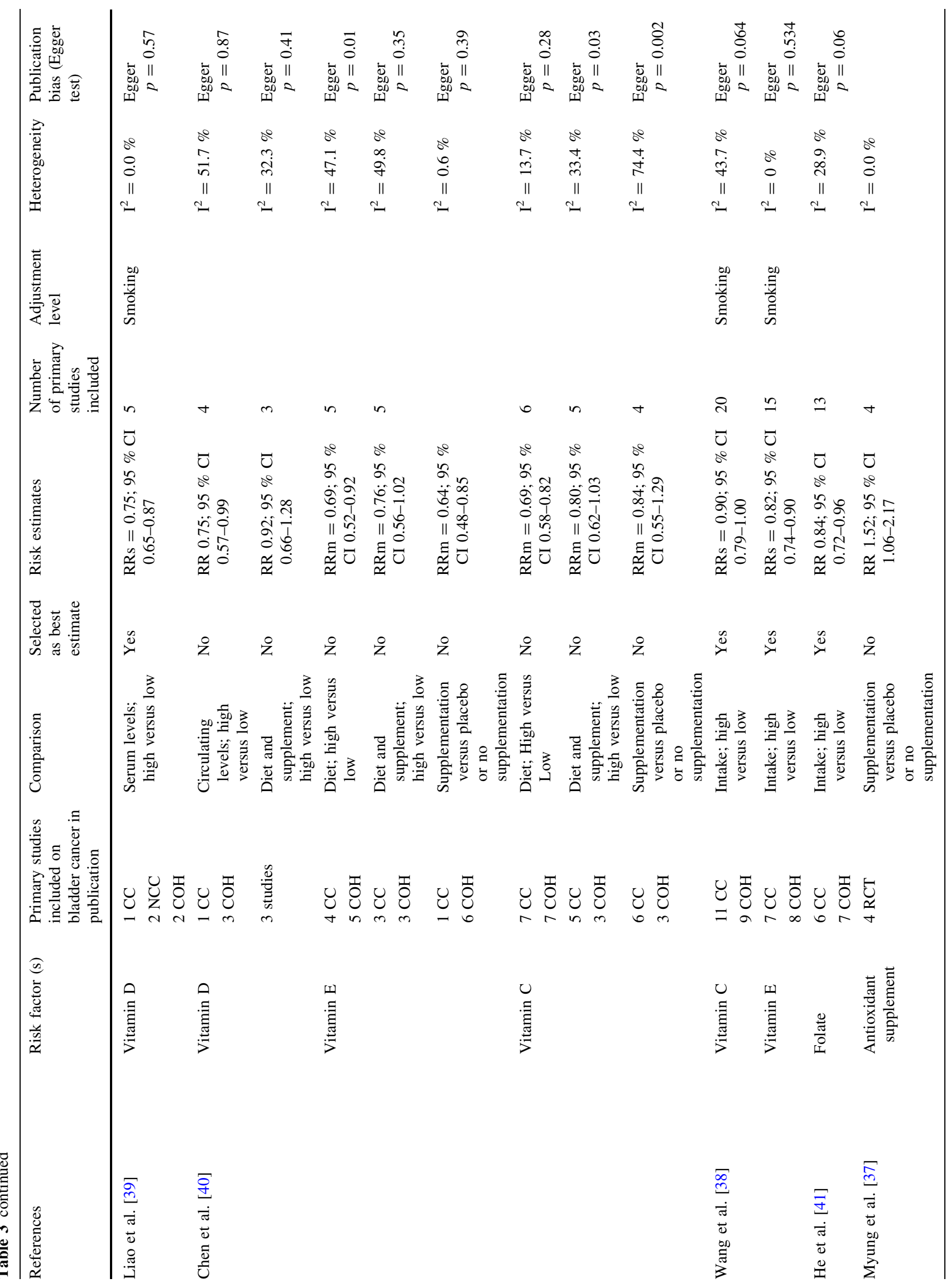




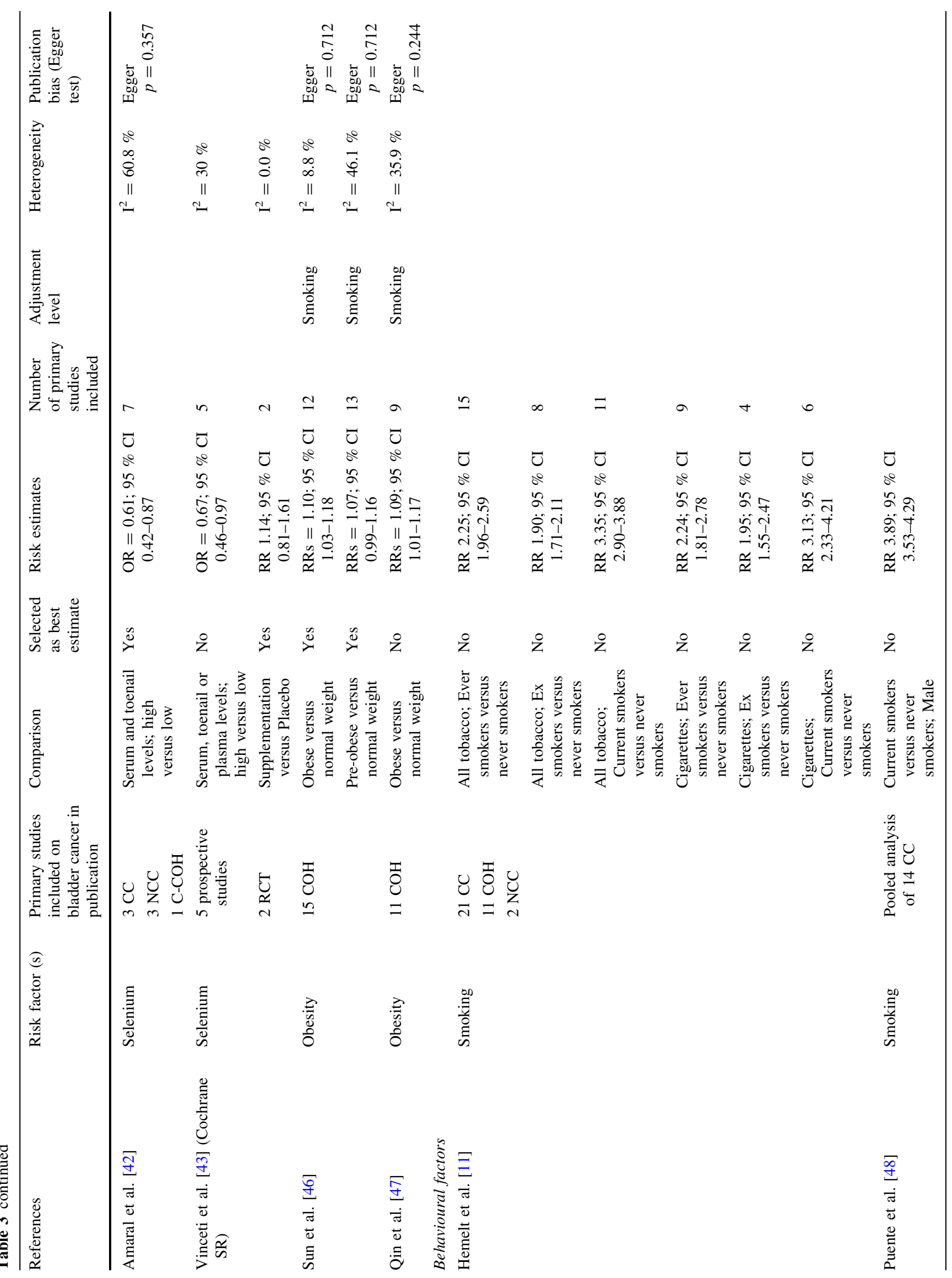









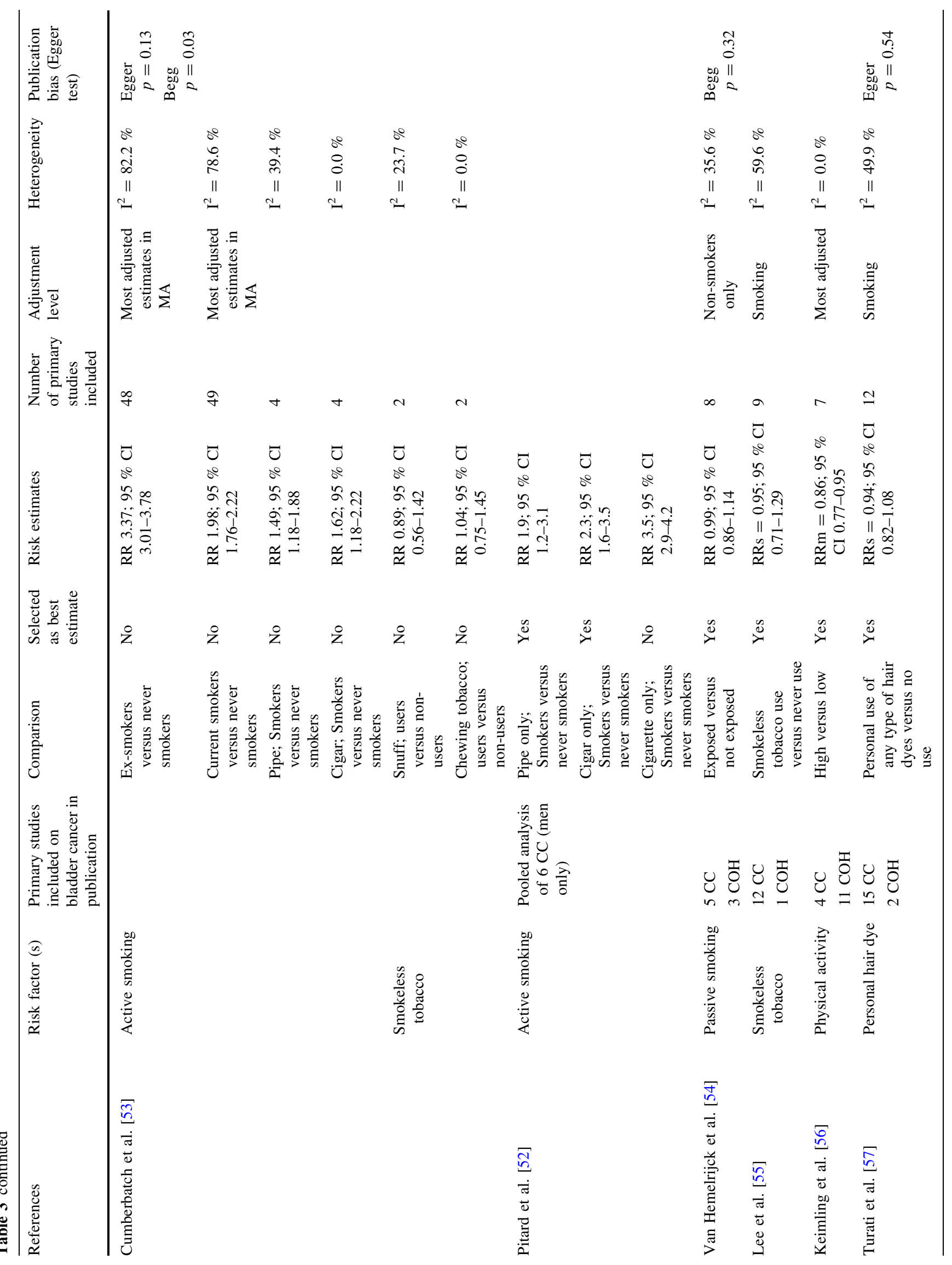




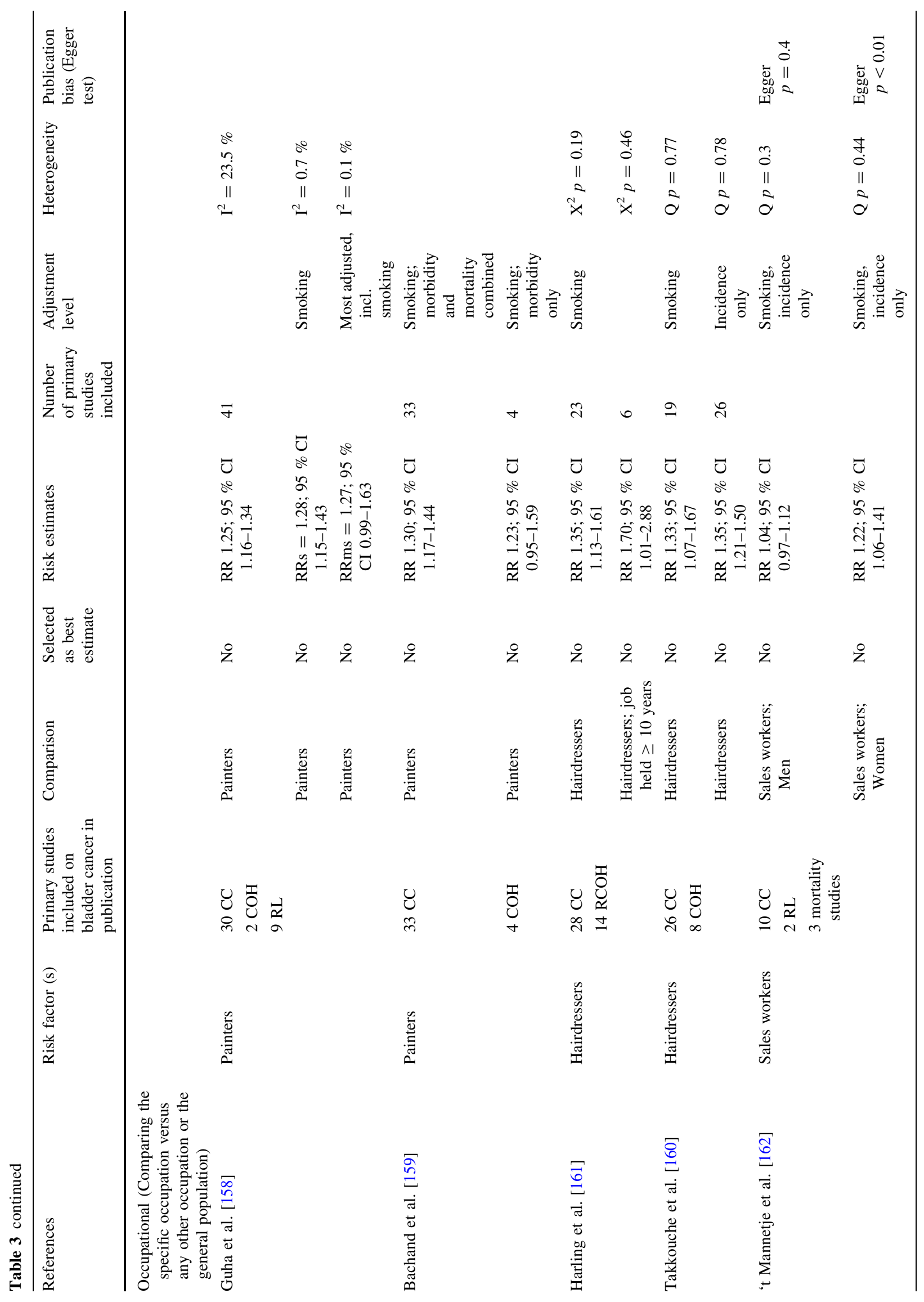




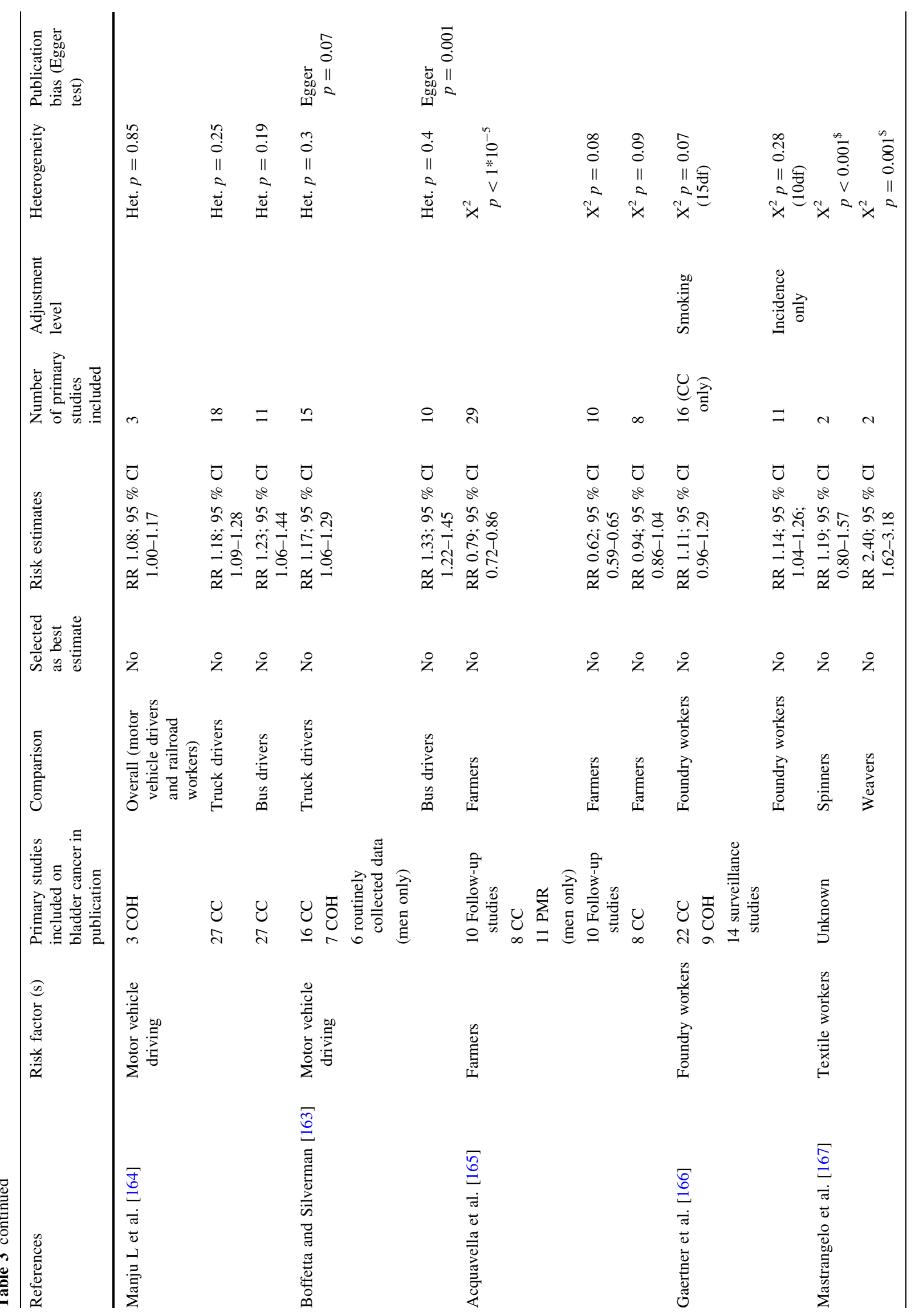




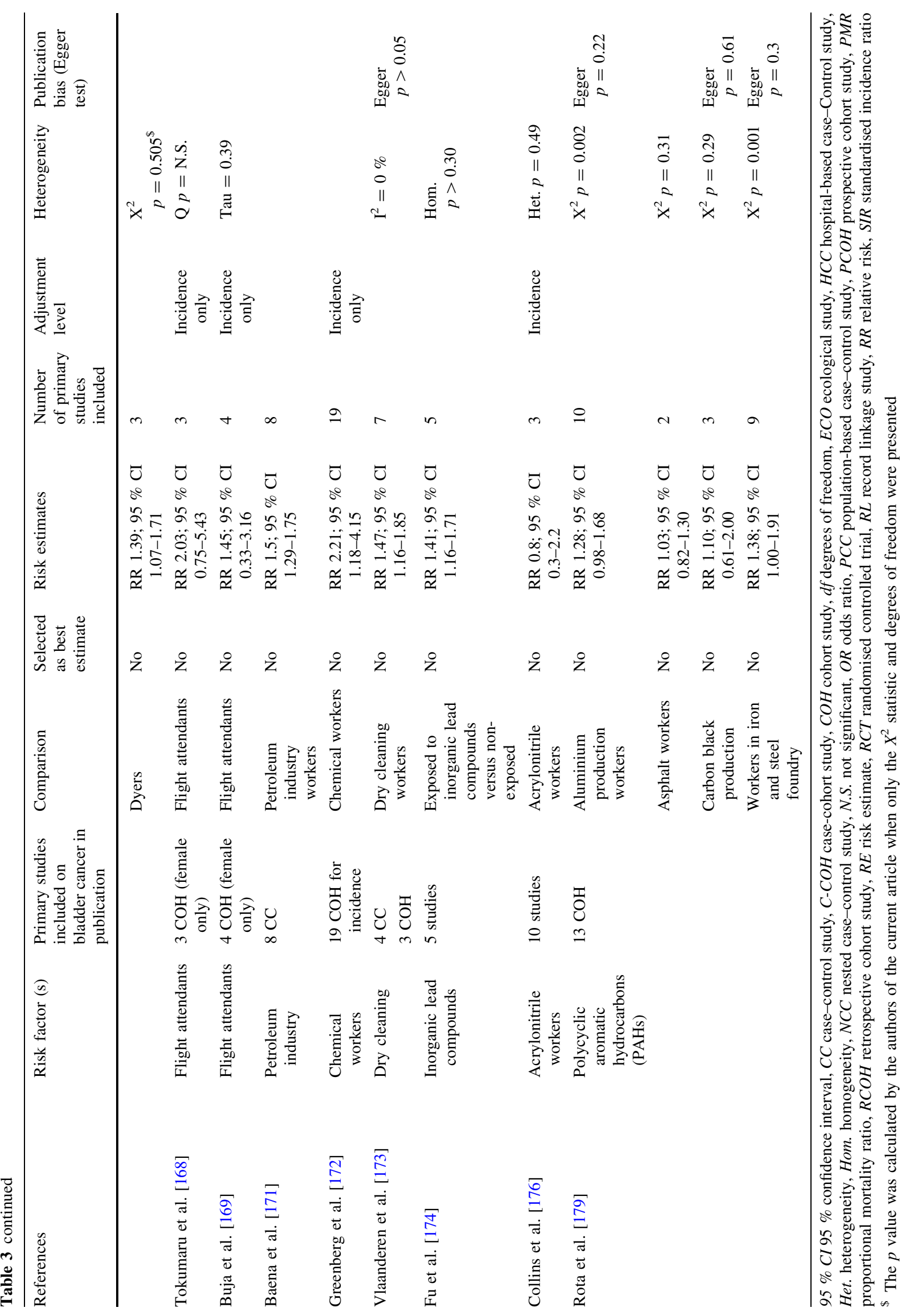




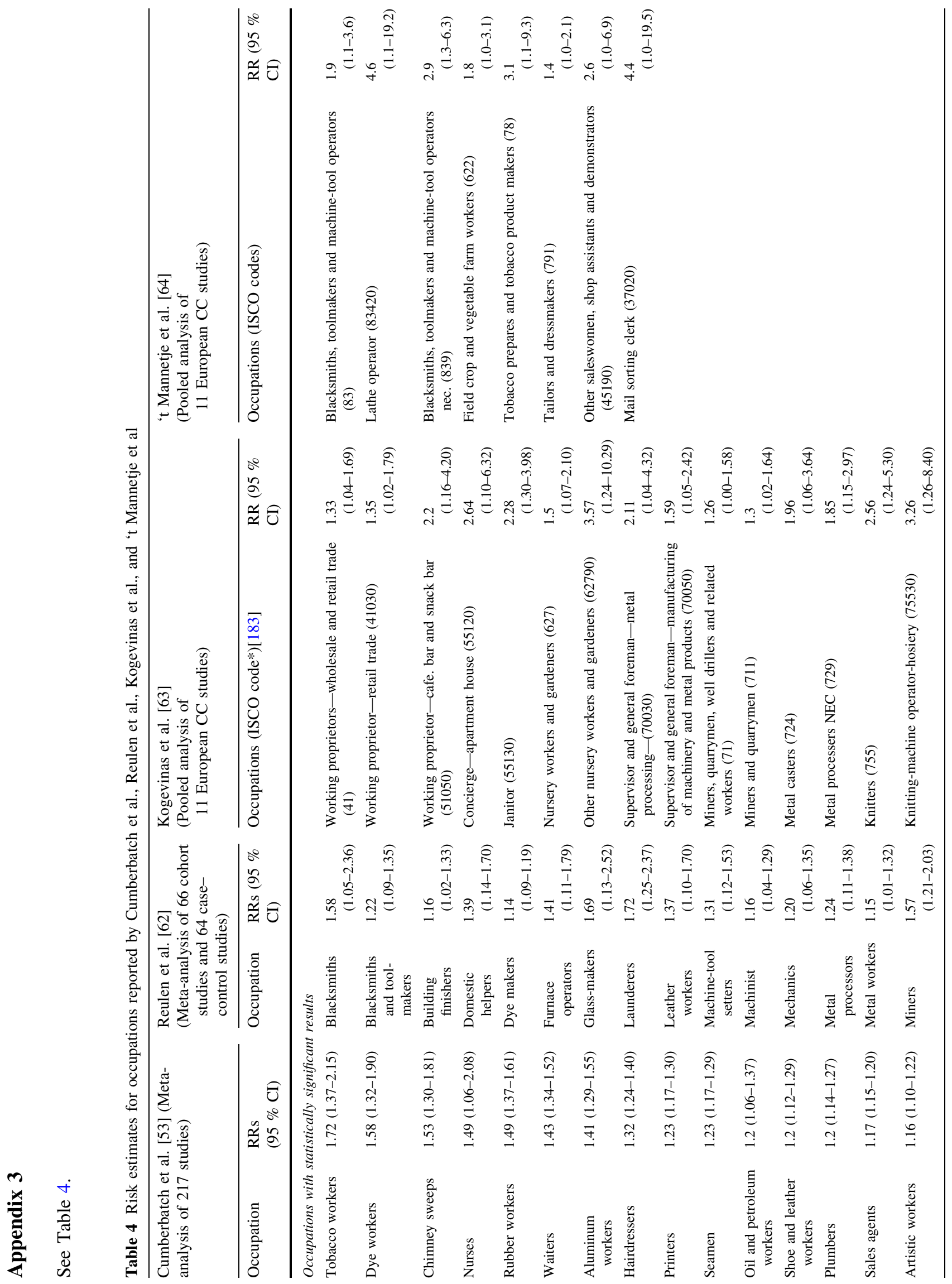




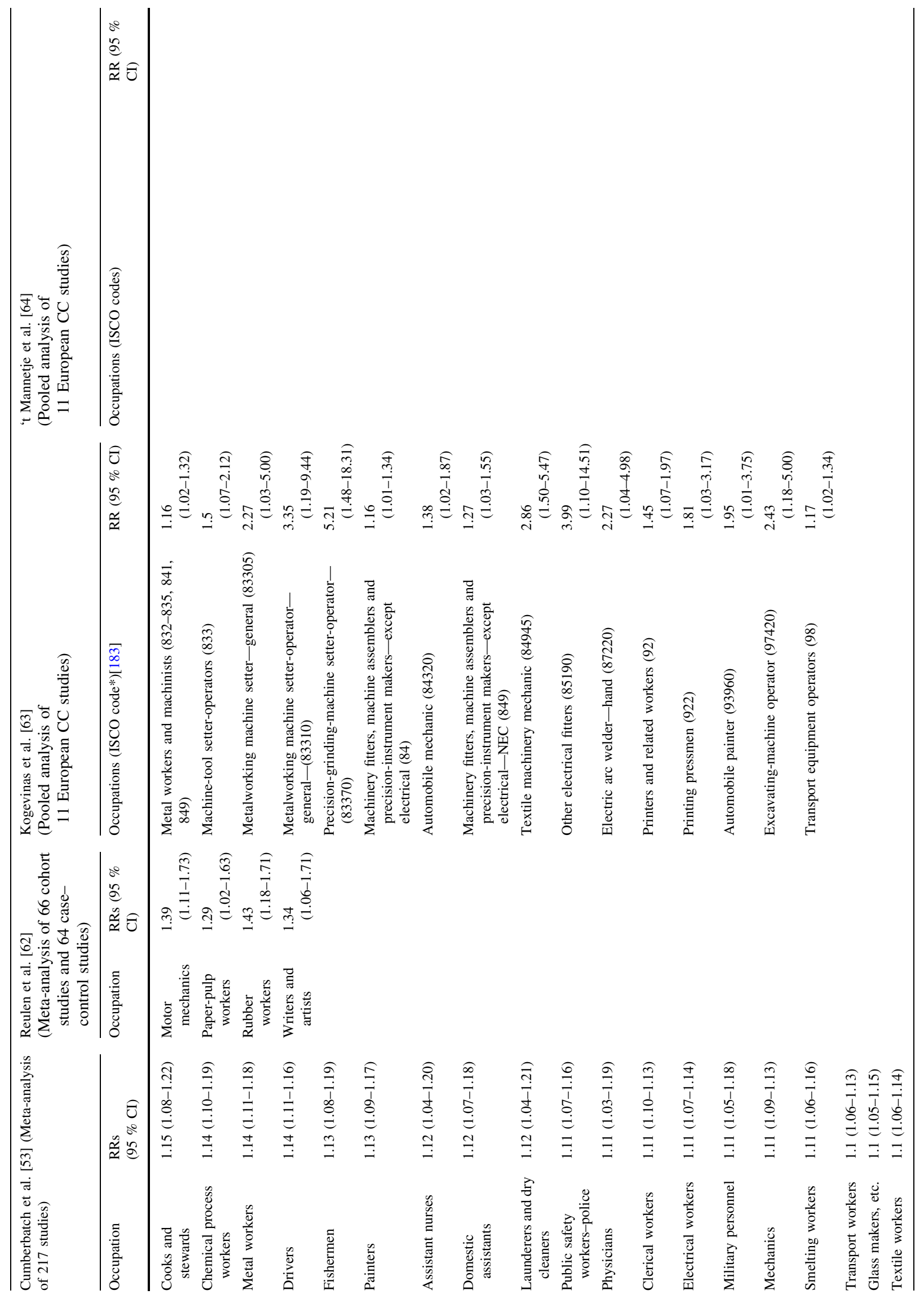




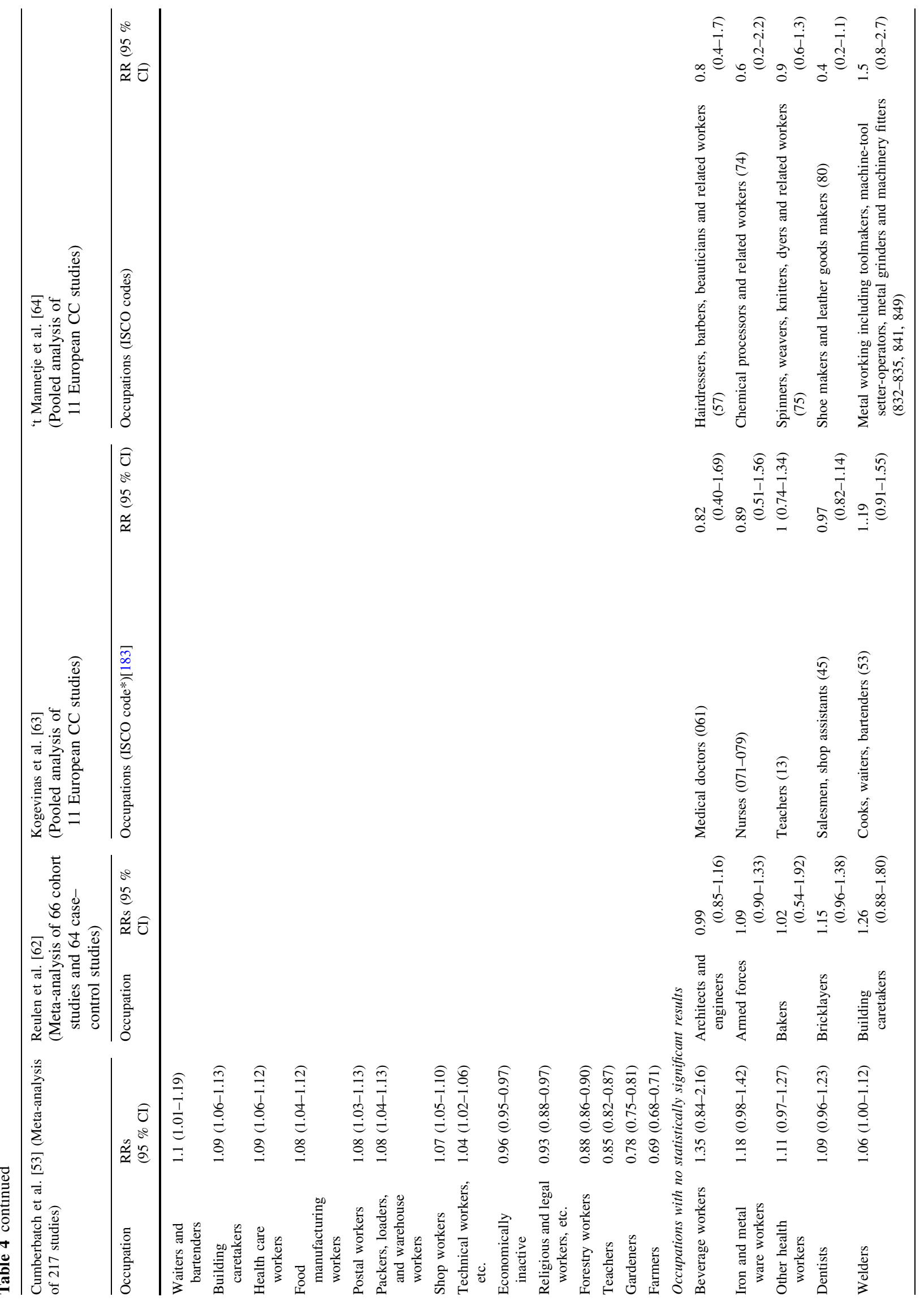




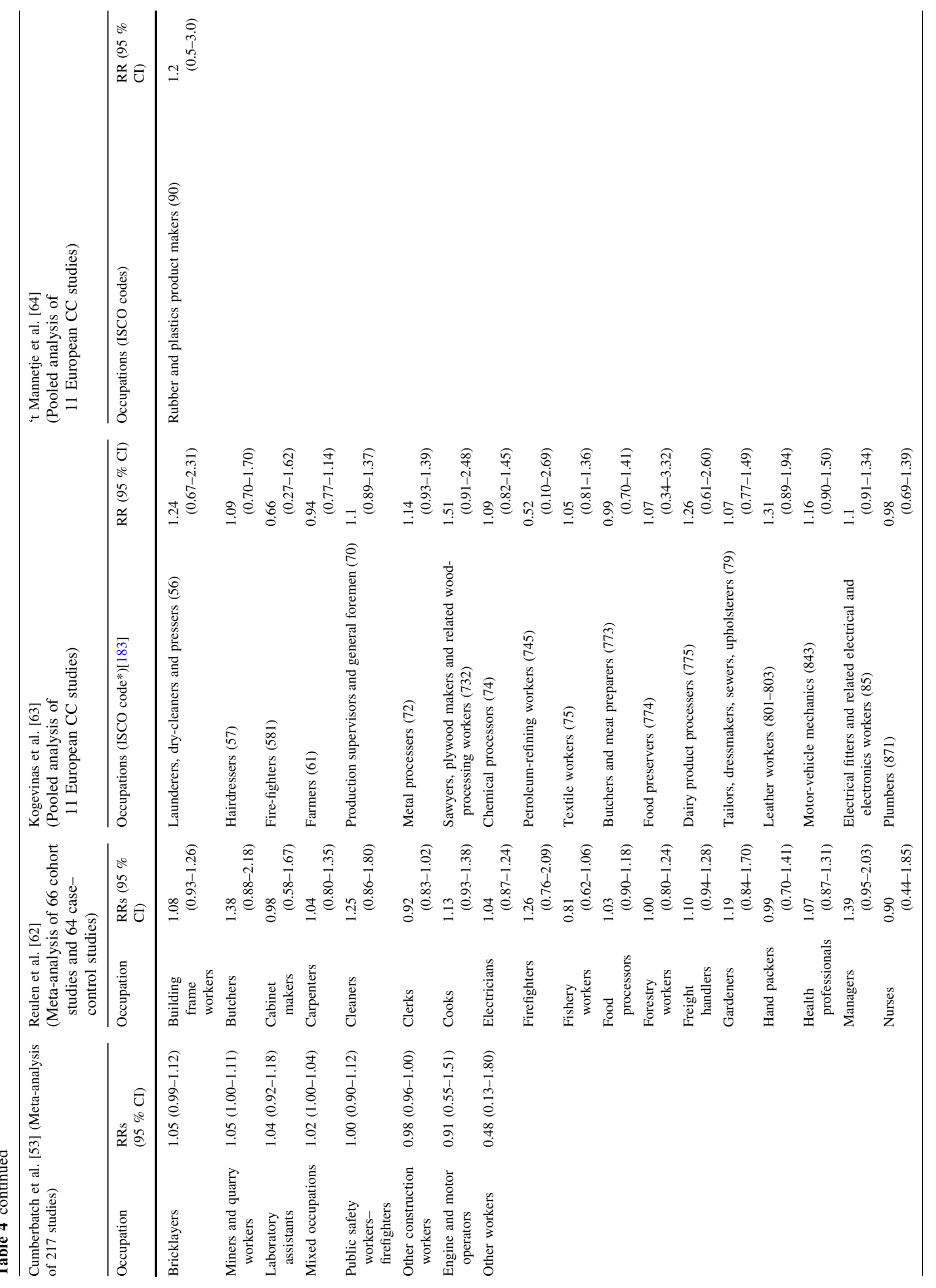




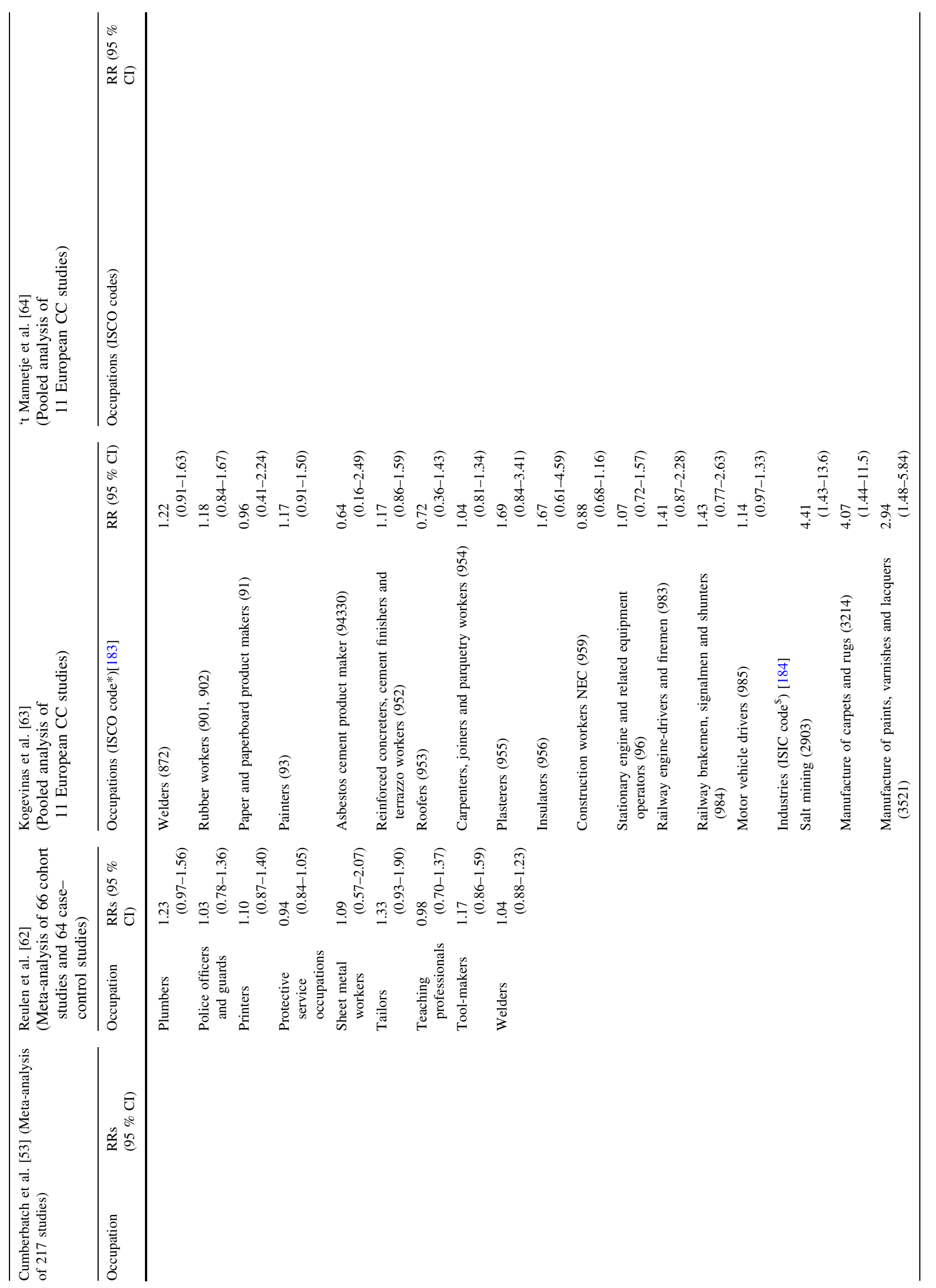




\section{References}

1. Cancer IA for R on. GLOBOCAN 2012: estimated cancer incidence, mortality and prevalence worldwide in 2012. World Heal. Organ. http//globocan. iarc. fr/Pages/fact_sheets_cancer. aspx. Accessed Sept 2014.

2. Czene K, Lichtenstein P, Hemminki K. Environmental and heritable causes of cancer among 9.6 million individuals in the Swedish family-cancer database. Int J Cancer. 2002;99:260-6.

3. Burger M, Catto JWF, Dalbagni G, Grossman HB, Herr H, Karakiewicz P, et al. Epidemiology and risk factors of urothelial bladder cancer. Eur Urol. 2013;63:234-41.

4. Chavan S, Bray F, Lortet-Tieulent J, Goodman M, Jemal A. International variations in bladder cancer incidence and mortality. Eur Urol. 2014;66:59-73.

5. Jemal A, Bray F, Center MM, Ferlay J, Ward E, Forman D. Global cancer statistics. CA Cancer J Clin. 2011;61:69-90.

6. Zeegers MPA, Kellen E, Buntinx F, van den Brandt PA. The association between smoking, beverage consumption, diet and bladder cancer: a systematic literature review. World J Urol. 2004;21:392-401.

7. Vineis P, Wild CP. Global cancer patterns: causes and prevention. Lancet. 2014;383:549-57.

8. Rushton L, Bagga S, Bevan R, Brown TP, Cherrie JW, Holmes P, et al. Occupation and cancer in Britain. $\mathrm{Br} \mathrm{J}$ Cancer. 2010;102:1428-37.

9. Ng M, Freeman MK, Fleming TD, Robinson M, Dwyer-Lindgren $\mathrm{L}$, Thomson $\mathrm{B}$, et al. Smoking prevalence and cigarette consumption in 187 countries, 1980-2012. JAMA. 2014;311: 183-92.

10. van Osch FHM, Jochems SHJ, van Schooten F-J, Bryan RT, Zeegers MPA. Quantified relations between exposure to tobacco smoking and bladder cancer risk: a meta-analysis of 89 studies. Manuscript submitted for publication. Int J Epidemiol. 2016. doi:10.1093/ije/dyw044.

11. Hemelt M, Yamamoto H, Cheng KK, Zeegers MPA. The effect of smoking on the male excess of bladder cancer: a meta-analysis and geographical analyses. Int J Cancer. 2009;124:412-9.

12. Clark PE, Agarwal N, Biagioli MC, Eisenberger MA, Greenberg RE, Herr HW, et al. Bladder cancer. J Natl Compr Cancer Netw. 2013;11:446-75.

13. Yeung C, Dinh T, Lee J. The health economics of bladder cancer: an updated review of the published literature. Pharmacoeconomics. 2014;32:1093-104.

14. Al-Zalabani A, Stewart K, Wesselius A, Zeegers M. Modifiable risk factors for the prevention of bladder cancer: a systematic review of meta-analyses. PROSPERO 2015:CRD42015023411 [Internet]. Available from: http://www.crd.york.ac.uk/PROS PERO/display_record.asp?ID=CRD42015023411.

15. Moher D, Liberati A, Tetzlaff J, Altman DG. Preferred reporting items for systematic reviews and meta-analyses: the PRISMA statement. BMJ. 2009;339:b2535.

16. Borenstein M, Hedges LV, Higgins JPT, Rothstein HR. Front matter. Introduction to meta-analysis. Chichester: Wiley; 2009.

17. Higgins JPT, Thompson SG, Deeks JJ, Altman DG. Measuring inconsistency in meta-analyses. BMJ. 2003;327:557-60.

18. Bouter LM, van Dongen MCJM, Zielhuis GA, Zeegers MP. Leerboek epidemiologie. Houten: Bohn Stafleu van Loghum; 2015.

19. Yao B, Yan Y, Ye X, Fang H, Xu H, Liu Y, et al. Intake of fruit and vegetables and risk of bladder cancer: a dose-response meta-analysis of observational studies. Cancer Causes Control. 2014;25:1645-58.

20. Liang S, Lv G, Chen W, Jiang J, Wang J. Citrus fruit intake and bladder cancer risk: a meta-analysis of observational studies. Int J Food Sci Nutr. 2014;7486:1-6. 
21. Steinmaus CM, Nuñez S, Smith AH. Diet and bladder cancer: a meta-analysis of six dietary variables. Am J Epidemiol. 2000;151:693-702.

22. Bai Y, Yuan H, Li J, Tang Y, Pu C, Han P. Relationship between bladder cancer and total fluid intake: a meta-analysis of epidemiological evidence. World J Surg Oncol Engl. 2014;12:223.

23. Qin J, Xie B, Mao Q, Kong D, Lin Y, Zheng X. Tea consumption and risk of bladder cancer: a meta-analysis. World $\mathrm{J}$ Surg Oncol Engl. 2012;10:172.

24. Huang T, Guo Z, Zhang X, Zhang X, Liu H, Geng J, et al. Coffee consumption and urologic cancer risk: a meta-analysis of cohort studies. Int Urol Nephrol. 2014;46:1481-93.

25. Zhou Y, Tian C, Jia C. A dose-response meta-analysis of coffee consumption and bladder cancer. Prev Med (Baltim). 2012;55:14-22.

26. Yu X, Bao Z, Zou J, Dong J. Coffee consumption and risk of cancers: a meta-analysis of cohort studies. BMC Cancer Engl. 2011;11:96.

27. Villanueva CM, Cantor KP, King WD, Jaakkola JJK, Cordier $\mathrm{S}$, Lynch $\mathrm{CF}$, et al. Total and specific fluid consumption as determinants of bladder cancer risk. Int $\mathrm{J}$ Cancer. 2006;118:2040-7.

28. Sala M, Cordier S, Chang-Claude J, Donato F, Escolar-Pujolar A, Fernandez F, et al. Coffee consumption and bladder cancer in nonsmokers: a pooled analysis of case-control studies in European countries. Cancer Causes Control. 2000;11:925-31.

29. Wu W, Tong Y, Zhao Q, Yu G, Wei X, Lu Q. Coffee consumption and bladder cancer: a meta-analysis of observational studies. Sci Rep. Macmillan Publishers Limited. All rights reserved; 2015; 5.

30. Boyle P, Koechlin A, Autier P. Sweetened carbonated beverage consumption and cancer risk: meta-analysis and review. Eur J Cancer Prev. 2014;23:481-90.

31. Mao Q-Q, Dai Y, Lin Y-W, Qin J, Xie L-P, Zheng X-Y. Milk consumption and bladder cancer risk: a meta-analysis of published epidemiological studies. Nutr Cancer. 2011;63:1263-71.

32. Li Z, Yu J, Miao Q, Sun S, Sun L, Yang H, et al. The association of fish consumption with bladder cancer risk: a meta-analysis. World J Surg Oncol. 2011;9:107.

33. Li F, An S, Hou L, Chen P, Lei C, Tan W. Red and processed meat intake and risk of bladder cancer: a meta-analysis. Int $\mathrm{J}$ Clin Exp Med. 2014;7:2100-10.

34. Pelucchi C, Galeone C, Tramacere I, Bagnardi V, Negri E, Islami $\mathrm{F}$, et al. Alcohol drinking and bladder cancer risk: a metaanalysis. Ann Oncol. 2012;23:1586-93.

35. Li F, Zhou Y, Hu R, Hou L, Du Y-J, Zhang X, et al. Egg consumption and risk of bladder cancer: a meta-analysis. Nutr Cancer. 2013;65:538-46.

36. Tang J-E, Wang R-J, Zhong H, Yu B, Chen Y. Vitamin A and risk of bladder cancer: a meta-analysis of epidemiological studies. World J Surg Oncol. 2014;12:130.

37. Jeon Y-J, Myung S-K, Lee E-H, Kim Y, Chang YJ, Ju W, et al. Effects of beta-carotene supplements on cancer prevention: meta-analysis of randomized controlled trials. Nutr Cancer. 2011;63:1196-207.

38. Wang Y-Y, Wang X-L, Yu Z-J. Vitamin C and E intake and risk of bladder cancer: a meta-analysis of observational studies. Int $\mathrm{J}$ Clin Exp Med. 2014;7:4154-64.

39. Liao Y, Huang JL, Qiu MX, Ma ZW. Impact of serum vitamin D level on risk of bladder cancer: a systemic review and metaanalysis. Tumour Biol. 2015;36:1567-72.

40. Chen F, Li Q, Yu Y, Yang W, Shi F, Qu Y. Association of vitamin $\mathrm{C}$, vitamin $\mathrm{D}$, vitamin $\mathrm{E}$ and risk of bladder cancer: a dose-response meta-analysis. Sci Rep Nat Publ Group. 2015;5:9599.
41. He H, Shui B. Folate intake and risk of bladder cancer: a metaanalysis of epidemiological studies. Int $\mathbf{J}$ Food Sci Nutr. 2014;65:286-92.

42. Amaral AFS, Cantor KP, Silverman DT, Malats N. Selenium and bladder cancer risk: a meta-analysis. Cancer Epidemiol Biomark Prev. 2010;19:2407-15.

43. Vinceti M, Dennert G, Crespi CM, Zwahlen M, Brinkman M, Zeegers MPA, et al. Selenium for preventing cancer. Cochrane Database Syst Rev. 2014;3:CD005195.

44. Myung S-K, Kim Y, Ju W, Choi HJ, Bae WK. Effects of antioxidant supplements on cancer prevention: meta-analysis of randomized controlled trials. Ann Oncol. 2010;21:166-79.

45. Pelucchi C, Bosetti C, Galeone C, La Vecchia C. Dietary acrylamide and cancer risk: an updated meta-analysis. Int $\mathbf{J}$ Cancer. 2015;136:2912-22.

46. Sun J-W, Zhao L-G, Yang Y, Ma X, Wang Y-Y, Xiang Y-B. Obesity and risk of bladder cancer: a dose-response metaanalysis of 15 cohort studies. PLoS ONE. 2015;10:e0119313.

47. Qin Q, Xu X, Wang X, Zheng X-Y. Obesity and risk of bladder cancer: a meta-analysis of cohort studies. Asian Pac J Cancer Prev. 2013;14:3117-21.

48. Puente D, Hartge P, Greiser E, Cantor KP, King WD, Gonzalez $\mathrm{CA}$, et al. A pooled analysis of bladder cancer case-control studies evaluating smoking in men and women. Cancer Causes Control Neth. 2006;17:71-9.

49. Freedman ND, Silverman DT, Hollenbeck AR, Schatzkin A, Abnet CC. Association between smoking and risk of bladder cancer among men and women. JAMA USA. 2011;306:737-45.

50. Brennan P, Bogillot O, Cordier S, Greiser E, Schill W, Vineis P, et al. Cigarette smoking and bladder cancer in men: a pooled analysis of 11 case-control studies. Int J Cancer. 2000;86:289-94.

51. Brennan P, Bogillot O, Greiser E, Chang-Claude J, Wahrendorf J, Cordier S, et al. The contribution of cigarette smoking to bladder cancer in women (pooled European data). Cancer Causes Control. 2001;12:411-7.

52. Pitard A, Brennan P, Clavel J, Greiser E, Lopez-Abente G, Chang-Claude J, et al. Cigar, pipe, and cigarette smoking and bladder cancer risk in European men. Cancer Causes Control. 2001;12:551-6.

53. Cumberbatch MG, Rota M, Catto JWF, La Vecchia C. The role of tobacco smoke in bladder and kidney carcinogenesis: a comparison of exposures and meta-analysis of incidence and mortality risks. Eur Urol 2015;1-9.

54. Van Hemelrijck MJJ, Michaud DS, Connolly GN, Kabir Z. Secondhand smoking, 4-aminobiphenyl, and bladder cancer: two meta-analyses. Cancer Epidemiol Biomark Prev. 2009;18:1312-20.

55. Lee PN, Hamling J. Systematic review of the relation between smokeless tobacco and cancer in Europe and North America. BMC Med. 2009; 7:36.

56. Keimling M, Behrens G, Schmid D, Jochem C, Leitzmann MF. The association between physical activity and bladder cancer: systematic review and meta-analysis. Br J Cancer. 2014;110:1862-70.

57. Turati F, Pelucchi C, Galeone C, Decarli A, La Vecchia C. Personal hair dye use and bladder cancer: a meta-analysis. Ann Epidemiol. 2014;24:151-9.

58. Kelsh MA, Alexander DD, Kalmes RM, Buffler PA. Personal use of hair dyes and risk of bladder cancer: a meta-analysis of epidemiologic data. Cancer Causes Control. 2008;19:549-58.

59. Huncharek M, Kupelnick B. Personal use of hair dyes and the risk of bladder cancer: results of a meta-analysis. Public Health Rep USA. 2005;120:31-8.

60. Takkouche B, Etminan M, Montes-Martínez A. Personal use of hair dyes and risk of cancer: a meta-analysis. JAMA. 2005;293:2516-25. 
61. Cumberbatch MGK, Cox A, Teare D, Catto JWF. Contemporary occupational carcinogen exposure and bladder cancer. JAMA Oncol. 2015;1:1282-90.

62. Reulen RC, Kellen E, Buntinx F, Brinkman M, Zeegers MP. A meta-analysis on the association between bladder cancer and occupation. Scand J Urol Nephrol Suppl. 2008;42:64-78.

63. Kogevinas M, 't Mannetje A, Cordier S, Ranft U, González $\mathrm{CA}$, Vineis $\mathrm{P}$, et al. Occupation and bladder cancer among men in Western Europe. Cancer Causes Control. 2003;14: 907-14.

64. Mannetje A, Kogevinas M, Chang-Claude J, Cordier S, Gonzalez CA, Hours M, et al. Occupation and bladder cancer in European women. Cancer Causes Control. 1999;10:209-17.

65. Clavel J, Cordier S, Boccon-Gibod L, Hemon D. Tobacco and bladder cancer in males: increased risk for inhalers and smokers of black tobacco. Int J Cancer. 1989;44:605-10.

66. D’Avanzo B, Negri E, La Vecchia C, Gramenzi A, Bianchi C, Franceschi S, et al. Cigarette smoking and bladder cancer. Eur J Cancer. 1990;26:714-8.

67. D’Avanzo B, La Vecchia C, Negri E, Decarli A, Benichou J. Attributable risks for bladder cancer in northern Italy. Ann Epidemiol. 1995;5:427-31.

68. Iscovich J, Castelletto R, Esteve J, Munoz N, Colanzi R, Coronel A, et al. Tobacco smoking, occupational exposure and bladder cancer in Argentina. Int J Cancer. 1987;40:734-40.

69. Momas I, Daures JP, Festy B, Bontoux J. Gremy F (1994) Bladder cancer and black tobacco cigarette smoking Some results from a French case-control study. Eur J Epidemiol. 1994;10:599-604.

70. De Stefani E, Correa P, Fierro L, Fontham E, Chen V, Zavala D. Black tobacco, mate, and bladder cancer. A case-control study from Uruguay. Cancer. 1991;67:536-40.

71. Samanic C, Kogevinas M, Dosemeci M, Malats N, Real FX, Garcia-Closas M, et al. Smoking and bladder cancer in Spain: effects of tobacco type, timing, environmental tobacco smoke, and gender. Cancer Epidemiol Biomark Prev. 2006;15:1348-54.

72. Cole P, Monson RR, Haning H, Friedell GH. Smoking and cancer $\mathrm{f}$ the lower urinary tract. $\mathrm{N}$ Engl $\mathrm{J}$ Med. 1971;284:129-34.

73. Morrison AS, Buring JE, Verhoek WG, Aoki K, Leck I, Ohno Y, et al. An international study of smoking and bladder cancer. J Urol. 1984;131:650-4.

74. Zeegers MPA, Goldbohm RA, van den Brandt PA. A prospective study on active and environmental tobacco smoking and bladder cancer risk (The Netherlands). Cancer Causes Control. 2002;13:83-90.

75. Lopez-Abente G, Gonzalez CA, Errezola M, Escolar A, Izarzugaza I, Nebot M, et al. Tobacco smoke inhalation pattern, tobacco type, and bladder cancer in Spain. Am J Epidemiol. 1991;134:830-9.

76. Burch JD, Rohan TE, Howe GR, Risch HA, Hill GB, Steele $\mathrm{R}$, et al. Risk of bladder cancer by source and type of tobacco exposure: a case-control study. Int J Cancer. 1989;44:622-8.

77. Hartge P, Silverman D, Hoover R, Schairer C, Altman R, Austin $\mathrm{D}$, et al. Changing cigarette habits and bladder cancer risk: a case-control study. J Natl Cancer Inst. 1987;78:1119-25.

78. Castelao JE, Yuan JM, Skipper PL, Tannenbaum SR, GagoDominguez M, Crowder JS, et al. Gender- and smoking-related bladder cancer risk. J Natl Cancer Inst. 2001;93:538-45.

79. Howe GR, Burch JD, Miller AB, Cook GM, Esteve J, Morrison $\mathrm{B}$, et al. Tobacco use, occupation, coffee, various nutrients, and bladder cancer. J Natl Cancer Inst. 1980;64:701-13.

80. Lockwood K. On the etiology of bladder tumors in KobenhavnFrederiksberg. An inquiry of 369 patients and 369 controls. Acta Pathol Microbiol. Scand. Suppl. Not Available; 1961;51(Suppl 1):1-166.
81. Hein DW. Molecular genetics and function of NAT1 and NAT2: role in aromatic amine metabolism and carcinogenesis. Mutat Res. 2002;506-507:65-77.

82. Centers for Disease Control and Prevention. How tobacco smoke causes disease: The biology and behavioral basis for smoking-attributable disease: A report of the surgeon general. Atlanta (GA); 2010.

83. Pelucchi C, Bosetti C, Negri E, Malvezzi M, La Vecchia C. Mechanisms of disease: The epidemiology of bladder cancer. Nat Clin Pract Urol. 2006;3:327-40.

84. Brinkman M, Zeegers MP. Nutrition, total fluid and bladder cancer. Scand J Urol Nephrol Suppl. 2008;42:25-36.

85. Liu RH. Potential synergy of phytochemicals in cancer prevention: mechanism of action. J Nutr. 2004;134:3479S-85S.

86. Talalay P, Fahey JW. Phytochemicals from cruciferous plants protect against cancer by modulating carcinogen metabolism. J Nutr. 2001;131:3027S-33S.

87. Kirk SF, Cade JE, Barrett JH, Conner M. Diet and lifestyle characteristics associated with dietary supplement use in women. Public Health Nutr. 1999;2:69-73.

88. Nutting CM, Huddart RA. Retinoids in the prevention of bladder cancer. Expert Rev Anticancer Ther. 2001;1:541-5.

89. International Agency for Research on Cancer. IARC Handbook of Cancer Prevention Volume 2: Carotenoids. Lyon, France: International Agency for Research on Cancer; 1998.

90. Stahl W, Sies H. Antioxidant activity of carotenoids. Mol Aspects Med. 2003;24:345-51.

91. Jiang Q. Natural forms of vitamin E: metabolism, antioxidant, and anti-inflammatory activities and their role in disease prevention and therapy. Free Radic Biol Med. 2014;72:76-90.

92. Balkwill F, Mantovani A. Inflammation and cancer: back to Virchow? Lancet (Lond). 2001;357:539-45.

93. Das S. Vitamin E in the genesis and prevention of cancer. A review. Acta Oncol. 1994;33:615-9.

94. Jackson MI, Combs GF. Selenium and anticarcinogenesis: underlying mechanisms. Curr Opin Clin Nutr Metab Care. 2008;11:718-26.

95. Mosby TT, Cosgrove M, Sarkardei S, Platt KL, Kaina B. Nutrition in adult and childhood cancer: role of carcinogens and anti-carcinogens. Anticancer Res. 2012;32:4171-92.

96. Micha R, Wallace SK, Mozaffarian D. Red and processed meat consumption and risk of incident coronary heart disease, stroke, and diabetes mellitus: a systematic review and meta-analysis. Circulation. 2010;121:2271-83.

97. Baena Ruiz R, Salinas Hernández P. Diet and cancer: risk factors and epidemiological evidence. Maturitas. 2014;77:202-8.

98. Choi SW, Mason JB. Folate and carcinogenesis: an integrated scheme. J Nutr. 2000;130:129-32.

99. Duthie SJ, Narayanan S, Brand GM, Pirie L, Grant G. Impact of folate deficiency on DNA stability. J Nutr. 2002;132:2444S-9S.

100. Ulrich CM, Potter JD. Folate and cancer-timing is everything. JAMA. 2007;297:2408.

101. Lee JE, Li H, Chan AT, Hollis BW, Lee I-M, Stampfer MJ, et al. Circulating levels of vitamin D and colon and rectal cancer: the Physicians' Health Study and a meta-analysis of prospective studies. Cancer Prev Res (Phila). 2011;4:735-43.

102. Kim Y, Je Y. Vitamin D intake, blood 25(OH)D levels, and breast cancer risk or mortality: a meta-analysis. Br J Cancer. 2014;110:2772-84.

103. Feldman D, Krishnan AV, Swami S, Giovannucci E, Feldman BJ. The role of vitamin D in reducing cancer risk and progression. Nat Rev Cancer. 2014;14:342-57.

104. Silberstein JL, Parsons JK. Evidence-based principles of bladder cancer and diet. Urology. 2010;75:340-6.

105. Villanueva CM, Fernández F, Malats N, Grimalt JO, Kogevinas M. Meta-analysis of studies on individual consumption of 
chlorinated drinking water and bladder cancer. J Epidemiol Community Health. 2003;57:166-73.

106. Costet N, Villanueva CM, Jaakkola JJK, Kogevinas M, Cantor KP, King WD, et al. Water disinfection by-products and bladder cancer: Is there a European specificity? A pooled and metaanalysis of European case-control studies. Occup Environ Med. 2011;68:379-85.

107. Tsuji JS, Alexander DD, Perez V, Mink PJ. Arsenic exposure and bladder cancer: quantitative assessment of studies in human populations to detect risks at low doses. Toxicology. 2014;317: $17-30$.

108. Chu H-A, Crawford-Brown DJ. Inorganic arsenic in drinking water and bladder cancer: a meta-analysis for dose-response assessment. Int J Environ Res Public Health. 2006;3:316-22.

109. Rogers CJ, Colbert LH, Greiner JW, Perkins SN, Hursting SD. Physical activity and cancer prevention: pathways and targets for intervention. Sports Med. 2008;38:271-96.

110. Letašiová S, Medve'ová A, Šovčíková A, Dušinská M, Volkovová K, Mosoiu C, et al. Bladder cancer, a review of the environmental risk factors. Environ Health. 2012;11(Suppl 1):S11.

111. Alavanja MCR, Bonner MR. Occupational pesticide exposures and cancer risk: a review. J Toxicol Environ Health B Crit Rev. 2012; 15:238-63.

112. Ntzani E, Chondrogiorgi M, Ntritsos G, Evangelou E, Tzoulaki I. Literature re view on epidemiological studies linking exposure to pesticides and health effect. EFSA supporting publication 2013:EN-497. 2013.

113. IAC Monographs on the Evaluation of Carcinogenic Risks to Humans, Volume 53, Occupational Exposures in Insecticide Application, and Some Pesticides. Lyon, France; 1991.

114. Tramèr MR, Reynolds DJ, Moore RA, McQuay HJ. Impact of covert duplicate publication on meta-analysis: a case study. BMJ. 1997;315:635-40.

115. Berrigan D, Dodd K, Troiano RP, Krebs-Smith SM, Barbash RB. Patterns of health behavior in U.S. adults. Prev Med (Baltim). 2003;36:615-23.

116. Lim SS, Vos T, Flaxman AD, Danaei G, Shibuya K, AdairRohani $\mathrm{H}$, et al. A comparative risk assessment of burden of disease and injury attributable to 67 risk factors and risk factor clusters in 21 regions, 1990-2010: a systematic analysis for the Global Burden of Disease Study 2010. Lancet. 2012;380: 2224-60.

117. Stein CJ, Colditz GA. Modifiable risk factors for cancer. $\mathrm{Br} \mathbf{J}$ Cancer. 2004;90:299-303.

118. Yusuf PS, Hawken S, Ônpuu S, Dans T, Avezum A, Lanas F, et al. Effect of potentially modifiable risk factors associated with myocardial infarction in 52 countries (the INTERHEART study): case-control study. Lancet. 2004;364:937-52.

119. Danaei G, Ding EL, Mozaffarian D, Taylor B, Rehm J, Murray CJL, et al. The preventable causes of death in the United States: comparative risk assessment of dietary, lifestyle, and metabolic risk factors. PLoS Med. 2009;6:e1000058.

120. Riboli E, Norat T. Epidemiologic evidence of the protective effect of fruit and vegetables on cancer risk. Am J Clin Nutr. 2003;78:559S-69S.

121. Liu B, Mao Q, Lin Y, Zhou F, Xie L. The association of cruciferous vegetables intake and risk of bladder cancer: a metaanalysis. World J Urol. 2013;31:127-33.

122. Vieira AR, Vingeliene S, Chan DSM, Aune D, Abar L, Navarro Rosenblatt D, et al. Fruits, vegetables, and bladder cancer risk: a systematic review and meta-analysis. Cancer Med. 2015;4: $136-46$.

123. Liu H, Wang X-C, Hu G-H, Guo Z-F, Lai P, Xu L, et al. Fruit and vegetable consumption and risk of bladder cancer. Eur $\mathrm{J}$ Cancer Prev. 2015;24:508-16.
124. Xu C, Zeng X-T, Liu T-Z, Zhang C, Yang Z-H, Li S, et al. Fruits and vegetables intake and risk of bladder cancer: a PRISMAcompliant systematic review and dose-response meta-analysis of prospective cohort studies. Medicine (Baltimore). 2015;94:e759.

125. Zeegers MP, Tan FE, Goldbohm RA, van den Brandt PA. Are coffee and tea consumption associated with urinary tract cancer risk? A systematic review and meta-analysis. Int $\mathbf{J}$ Epidemiol. 2001;30:353-62.

126. Zhang Y-F, Xu Q, Lu J, Wang P, Zhang H-W, Zhou L, et al. Tea consumption and the incidence of cancer: a systematic review and meta-analysis of prospective observational studies. Eur $\mathbf{J}$ Cancer Prev. 2015;24:353-62.

127. Wu S, Li F, Huang X, Hua Q, Huang T, Liu Z, et al. The association of tea consumption with bladder cancer risk: a metaanalysis. Asia Pac J Clin Nutr. 2013;22:128-37.

128. Wang X, Lin Y-W, Wang S, Wu J, Mao Q-Q, Zheng X-Y, et al. A meta-analysis of tea consumption and the risk of bladder cancer. Urol Int. 2013;90:10-6.

129. Boehm K, Borrelli F, Ernst E, Habacher G, Hung SK, Milazzo $\mathrm{S}$, et al. Green tea (Camellia sinensis) for the prevention of cancer. Cochrane Database Syst Rev. 2009. doi:10.1002/ 14651858.CD005004.pub2.

130. Qin J, Xie B, Mao Q, Kong D, Lin Y, Zheng X. Tea consumption and risk of bladder cancer: a meta-analysis. World $\mathrm{J}$ Surg Oncol. 2012;10:172.

131. Arab L. Epidemiologic evidence on coffee and cancer. Nutr Cancer. 2010;62:271-83.

132. Pelucchi C, La Vecchia C. Alcohol, coffee, and bladder cancer risk: a review of epidemiological studies. Eur J Cancer Prev. 2009;18:62-8.

133. Zhang Z-H, Yang L-S, Sun Y-H. The association between milk consumption and bladder cancer risk: appraisal of a recent metaanalysis. Nutr Cancer. 2012;64:1288-9.

134. Lampe JW. Dairy products and cancer. J Am Coll Nutr. 2011;30:464S-70S

135. Li F, An S, Zhou Y, Liang Z, Jiao Z, Jing Y, et al. Milk and dairy consumption and risk of bladder cancer: a meta-analysis. Urology. 2011;78:1298-305.

136. Wang $\mathrm{C}$, Jiang $\mathrm{H}$. Meat intake and risk of bladder cancer: a meta-analysis. Med Oncol. 2012;29:848-55.

137. Mao Q, Lin Y, Zheng X, Qin J, Yang K, Xie L. A meta-analysis of alcohol intake and risk of bladder cancer. Cancer Causes Control. 2010;21:1843-50.

138. de Menezes RF, Bergmann A, Thuler LCS. Alcohol consumption and risk of cancer: a systematic literature review. Asian Pac J Cancer Prev. 2013;14:4965-72.

139. Bagnardi V, Blangiardo M, La Vecchia C, Corrao G. A metaanalysis of alcohol drinking and cancer risk. Br $\mathrm{J}$ Cancer. 2001;85:1700-5.

140. Zeegers MP, Tan FE, Verhagen AP, Weijenberg MP, van den Brandt PA. Elevated risk of cancer of the urinary tract for alcohol drinkers: a meta-analysis. Cancer Causes Control. 1999;10:445-51.

141. Fang D, Tan F, Wang C, Zhu X, Xie L. Egg intake and bladder cancer risk: a meta-analysis. Exp Ther Med. 2012;4:906-12.

142. Musa-Veloso K, Card JW, Wong AW, Cooper DA. Influence of observational study design on the interpretation of cancer risk reduction by carotenoids. Nutr Rev. 2009;67:527-45.

143. Coulter ID, Hardy ML, Morton SC, Hilton LG, Tu W, Valentine D, et al. Antioxidants vitamin $\mathrm{C}$ and vitamin e for the prevention and treatment of cancer. J Gen Intern Med. 2006;21:735-44.

144. MacLean CH, Newberry SJ, Mojica WA, Khanna P, Issa AM, Suttorp MJ, et al. Effects of omega-3 fatty acids on cancer risk: a systematic review. JAMA. 2006;295:403-15. 
145. Mao S, Huang S. Zinc and copper levels in bladder cancer: a systematic review and meta-analysis. Biol Trace Elem Res. 2013;153:5-10.

146. Psaltopoulou T, Kosti RI, Haidopoulos D, Dimopoulos M, Panagiotakos DB. Olive oil intake is inversely related to cancer prevalence: a systematic review and a meta-analysis of 13,800 patients and 23,340 controls in 19 observational studies. Lipids Health Dis. 2011;10:127.

147. Lotan Y, Daudon M, Bruyère F, Talaska G, Strippoli G, Johnson $\mathrm{RJ}$, et al. Impact of fluid intake in the prevention of urinary system diseases: a brief review. Curr Opin Nephrol Hypertens. 2013;22(Suppl 1):S1-10.

148. Stelmach R, Clasen T. Household water quantity and health: a systematic review. Int J Environ Res Public Health. 2015;12: $5954-74$.

149. Zeegers MP, Tan FE, Dorant E, van Den Brandt PA. The impact of characteristics of cigarette smoking on urinary tract cancer risk: a meta-analysis of epidemiologic studies. Cancer. 2000;89:630-9.

150. Crivelli JJ, Xylinas E, Kluth LA, Rieken M, Rink M, Shariat SF. Effect of smoking on outcomes of urothelial carcinoma: a systematic review of the literature. Eur Urol. 2014;65:742-54.

151. Sasco AJ, Secretan MB, Straif K. Tobacco smoking and cancer: a brief review of recent epidemiological evidence. Lung Cancer. 2004;45(Suppl 2):S3-9.

152. Vineis P, Alavanja M, Garte S. Dose-response relationship in tobacco-related cancers of bladder and lung: a biochemical interpretation. Int J Cancer. 2004;108:2-7.

153. Shiels MS, Gibson T, Sampson J, Albanes D, Andreotti G, Beane Freeman L, et al. Cigarette smoking prior to first cancer and risk of second smoking-associated cancers among survivors of bladder, kidney, head and neck, and stage I lung cancers. J Clin Oncol. 2014;32:3989-95.

154. 't Mannetje A, Kogevinas M, Chang-Claude J, Cordier S, González CA, Hours M, et al. Smoking as a confounder in casecontrol studies of occupational bladder cancer in women. Am J Ind Med. 1999;36:75-82.

155. Akl EA, Gaddam S, Gunukula SK, Honeine R, Jaoude PA, Irani J. The effects of waterpipe tobacco smoking on health outcomes: a systematic review. Int J Epidemiol. 2010;39:834-57.

156. Rollison DE, Helzlsouer KJ, Pinney SM. Personal hair dye use and cancer: a systematic literature review and evaluation of exposure assessment in studies published since 1992. J Toxicol Environ Health B Crit Rev. 2006;9:413-39.

157. Bosetti C, Pira E, La Vecchia C. Bladder cancer risk in painters: a review of the epidemiological evidence, 1989-2004. Cancer Causes Control. 2005;16:997-1008.

158. Guha N, Steenland NK, Merletti F, Altieri A, Cogliano V, Straif K. Bladder cancer risk in painters: a meta-analysis. Occup Environ Med. 2010;67:568-73.

159. Bachand A, Mundt KA, Mundt DJ, Carlton LE. Meta-analyses of occupational exposure as a painter and lung and bladder cancer morbidity and mortality 1950-2008. Crit Rev Toxicol. 2010;40:101-25.

160. Takkouche B, Regueira-Méndez C, Montes-Martínez A. Risk of cancer among hairdressers and related workers: a meta-analysis. Int J Epidemiol. 2009;38:1512-31.

161. Harling M, Schablon A, Schedlbauer G, Dulon M, Nienhaus A. Bladder cancer among hairdressers: a meta-analysis. Occup Environ Med. 2010;67:351-8.

162. 't Mannetje A, Pearce N. Bladder cancer risk in sales workers: artefact or cause for concern? Am J Ind Med. 2006;49:175-86.

163. Boffetta P, Silverman DT. A meta-analysis of bladder cancer and diesel exhaust exposure. Epidemiology. 2001;12:125-30.

164. Manju L, George PS, Mathew A. Urinary bladder cancer risk among motor vehicle drivers: a meta-analysis of the evidence, 1977-2008. Asian Pac J Cancer Prev. 2009;10:287-94.
165. Acquavella J, Olsen G, Cole P, Ireland B, Kaneene J, Schuman $\mathrm{S}$, et al. Cancer among farmers: a meta-analysis. Ann Epidemiol. 1998;8:64-74.

166. Gaertner RRW, Thériault GP. Risk of bladder cancer in foundry workers: a meta-analysis. Occup Environ Med. 2002;59:655-63.

167. Mastrangelo G, Fedeli U, Fadda E, Milan G, Lange JH. Epidemiologic evidence of cancer risk in textile industry workers: a review and update. Toxicol Ind Health. 2002;18:171-81.

168. Tokumaru O, Haruki K, Bacal K, Katagiri T, Yamamoto T, Sakurai Y. Incidence of cancer among female flight attendants: a meta-analysis. J Travel Med. 2006;13:127-32.

169. Buja A, Mastrangelo G, Perissinotto E, Grigoletto F, Frigo AC, Rausa G, et al. Cancer Incidence among female flight attendants: a meta-analysis of published data. J Women's Heal. 2006;15:98-105.

170. Wong O, Raabe GK. A critical review of cancer epidemiology in the petroleum industry, with a meta-analysis of a combined database of more than 350,000 workers. Regul Toxicol Pharmacol. 2000;32:78-98.

171. Baena AV, Allam MF, Díaz-Molina C, Del Castillo AS, AbdelRahman AG, Navajas RF-C. Urinary bladder cancer and the petroleum industry: a quantitative review. Eur J Cancer Prev. 2006;15:493-7.

172. Greenberg RS, Mandel JS, Pastides H, Britton NL, Rudenko L, Starr TB. A meta-analysis of cohort studies describing mortality and cancer incidence among chemical workers in the United States and western Europe. Epidemiology. 2001;12:727-40.

173. Vlaanderen J, Straif K, Ruder A, Blair A, Hansen J, Lynge E, et al. Tetrachloroethylene exposure and bladder cancer risk: a meta-analysis of dry-cleaning-worker studies. Environ Health Perspect. 2014;122:661-6.

174. Fu H, Boffetta P. Cancer and occupational exposure to inorganic lead compounds: a meta-analysis of published data. Occup Environ Med. 1995;52:73-81.

175. Cole P, Mandel JS, Collins JJ. Acrylonitrile and cancer: a review of the epidemiology. Regul Toxicol Pharmacol. 2008;52:342-51.

176. Collins JJ, Acquavella JF. Review and meta-analysis of studies of acrylonitrile workers. Scand J Work Environ Health. 1998;24(Suppl 2):71-80.

177. Bosetti C, Boffetta P, La Vecchia C. Occupational exposures to polycyclic aromatic hydrocarbons, and respiratory and urinary tract cancers: a quantitative review to 2005. Ann Oncol. 2007; 18:431-46.

178. Boffetta P, Jourenkova N, Gustavsson P. Cancer risk from occupational and environmental exposure to polycyclic aromatic hydrocarbons. Cancer Causes Control. 1997;8:444-72.

179. Rota M, Bosetti C, Boccia S, Boffetta P, La Vecchia C. Occupational exposures to polycyclic aromatic hydrocarbons and respiratory and urinary tract cancers: an updated systematic review and a meta-analysis to 2014. Arch Toxicol. 2014;88:1479-90.

180. Calvert GM, Ward E, Schnorr TM, Fine LJ. Cancer risks among workers exposed to metalworking fluids: a systematic review. Am J Ind Med. 1998;33:282-92.

181. Mundt KA, Birk T, Burch MT. Critical review of the epidemiological literature on occupational exposure to perchloroethylene and cancer. Int Arch Occup Environ Health. 2003;76:473-91.

182. Goodman M, Morgan RW, Ray R, Malloy CD, Zhao K. Cancer in asbestos-exposed occupational cohorts: a meta-analysis. Cancer Causes Control. 1999;10:453-65.

183. International Labour Office (ILO). International Standard Classification of Occupations. Revised Edition 1968. Geneva: International Labour Office (ILO); 1969.

184. Statistical Office of the United Nations. International standard industrial classification of all economic activities. Statistical papers series M, number 4, revision 2. 1968. 